\title{
Epithelial Cell Polarity and Cell JUNCTIONS IN DROSOPHILA
}

\author{
Ulrich Tepass and Guy Tanentzapf \\ Department of Zoology, University of Toronto, 25 Harbord Street, Toronto, Ontario \\ M5S3G5,Canada; e-mail: utepass@zoo.utoronto.ca, guy@zoo.utoronto.ca \\ Robert Ward and Richard Fehon \\ DCMB Group, Department of Biology, Duke University, B333 LSRC Research Drive, \\ Durham, North Carolina 27708; e-mail: rward@howard.genetics.utah.edu; \\ rfehon@duke.edu
}

Key Words epithelium, polarity, cellular junctions, cellularization, membrane domain

Abstract The polarized architecture of epithelial cells and tissues is a fundamental determinant of animal anatomy and physiology. Recent progress made in the genetic and molecular analysis of epithelial polarity and cellular junctions in Drosophila has led to the most detailed understanding of these processes in a whole animal model system to date. Asymmetry of the plasma membrane and the differentiation of membrane domains and cellular junctions are controlled by protein complexes that assemble around transmembrane proteins such as DE-cadherin, Crumbs, and Neurexin IV, or other cytoplasmic protein complexes that associate with the plasma membrane. Much remains to be learned of how these complexes assemble, establish their polarized distribution, and contribute to the asymmetric organization of epithelial cells.

\section{CONTENTS}

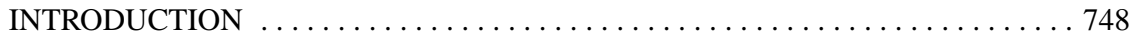

EPITHELIAL DIFFERENTIATION IN DROSOPHILA: AN OVERVIEW . . . . . 749

Development of Primary and Secondary Epithelia . . . . . . . . . . . . . . . . 749

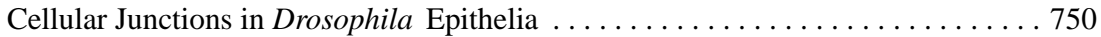

EPITHELIUM FORMATION: CELLULARIZATION $\ldots \ldots \ldots \ldots \ldots \ldots \ldots \ldots . \ldots 751$

PROTEIN COMPLEXES INVOLVED IN SPECIFICATION AND

REGIONALIZATION OF EPITHELIAL SURFACE DOMAINS . . . . . . . . 754

Adherens Junctions and the Cadherin-Catenin Complex . . . . . . . . . . . 755

Adherens Junctions and Cell Signaling . . . . . . . . . . . . . . . . . . 757

Apical Polarization I: The Crumbs/Stardust/Discs

Lost Complex . . . . . . . . . . . . . . . . . . . . . . . . . 759

Apical Polarization II: The Bazooka/aPKC/DPar-6 Complex . . . . . . . . . . 761

Apical Polarization III: The Lethal Giant Larvae/Discs

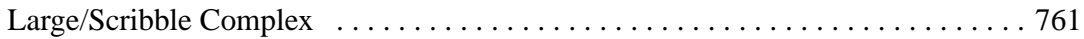




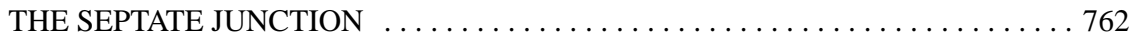

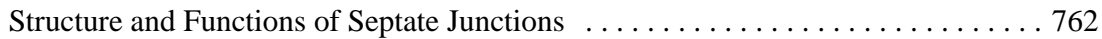

Molecular Architecture of the Septate Junction $\ldots \ldots \ldots \ldots \ldots \ldots \ldots . \ldots . \ldots 764$

Relationship between the Insect Epithelial and the Vertebrate

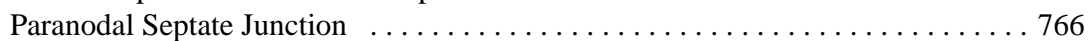

TIGHT JUNCTIONS IN DROSOPHILA? . . . . . . . . . . . . . . . 769

THE SPECTRIN CYTOSKELETON IN

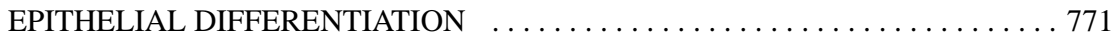

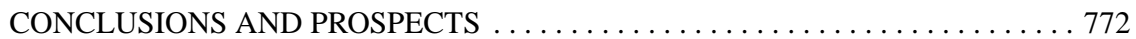

\section{INTRODUCTION}

Epithelial tissues have emerged early during animal evolution, and their ability to form different shapes and to subdivide the body into physiologically distinct compartments is fundamental for the evolution of complex animal body plans. The plasma membrane of epithelial cells is subdivided into regions or domains that fulfill specialized roles in cell organization and physiology. The main subdivisions of the plasma membrane are the apical domain, which faces the external environment and the basolateral domain, which is in contact with the interstitial space of the body. These domains are segregated by a circumferential junctional complex (CJC) that binds adjacent epithelial cells together and forms a semipermeable barrier to the diffusion of solutes through the intercellular space (38). The movement of ions and molecules across an epithelial layer therefore requires regulated transport mechanisms that shuttle solutes from apical to basolateral, or vice versa, and allow epithelia to control the physiological composition of body compartments. In addition to the apical/basolateral distinction, membrane domains of epithelial cells are further regionalized. The basolateral membrane, for example, is subdivided into a basal domain characterized by cell-substrate adhesion and a lateral domain distinguished by cell-cell adhesion. Further, the lateral domain is partitioned into the apical CJC and a region basal to it (121).

The mechanisms that establish and maintain an asymmetric distribution of lipid and protein components of the plasma membrane of epithelial cells have been intensively studied in mammalian cell culture (100). Early work in this system led to a model suggesting that the sorting of plasma membrane components in the Trans-Golgi Network (TGN) into apical and basolateral transport vesicles and the subsequent polarized delivery to the appropriate surface domain are the key mechanisms by which epithelial polarity is maintained (130). However, this model failed to explain how apical and basolateral domains are established initially, and how the two main surface domains are further regionalized. Moreover, it was recognized that apical and basolateral transport vesicles are also formed in nonpolarized cells in which the components of such vesicles show overlapping distributions in the plasma membrane $(98,186)$.

Analysis of the role of cell adhesion and its consequences on cellular organization led to the current conceptual framework of epithelial polarity $(30,100)$. 
External cues mediated by cell-cell or cell-substrate adhesion generate asymmetries within the plasma membrane that are elaborated by the formation of a local specific membrane cytoskeleton. Retention of transmembrane and cytoplasmic proteins that associate with this local actin/spectrin cytoskeleton emphasize regional differences (92). These differences are further elaborated by adhesiondependent reorganization of the microtubule cytoskeleton that is necessary for vesicle traffic, and the formation of targeting patches at the lateral membrane that preferentially attract basolateral transport vesicles $(51,185)$. This model of membrane domain formation integrates several interdependent polarization mechanisms, the concerted activity of which is triggered by adhesive interactions that provide positional cues for cell polarization. The formation of the apical domain is thus viewed as a default pathway in which the plasma membrane assumes apical character wherever no adhesive interactions take place.

Using Drosophila as a genetic model to study epithelial polarization offers the opportunity to complement and expand on the mammalian cell culture studies by placing the mechanisms that control epithelial differentiation into a developmental context. Genetic screens have identified a number of factors essential for epithelial polarity that are either integral to, or associated with, the plasma membrane, but did not reveal components of the TGN that contribute to the formation of apical or basolateral transport vesicles. These findings are consistent with a predominant role of extrinsic cues mediated by transmembrane adhesion receptors and cytocortical factors in epithelial polarization. Work using Drosophila also revealed a number of regulators of epithelial polarity that are associated with the apical membrane, suggesting that the formation of the apical domain is not a default pathway but instead requires a specific molecular machinery. Finally, studies on Drosophila are beginning to reveal an unforeseen complexity in the mechanisms controlling epithelial polarization that may vary from tissue to tissue and over time in the same tissue. This review gives an overview of epithelial development in Drosophila, with emphasis on recent studies that have provided novel insights into polarity and the differentiation and function of cellular junctions in epithelial cells.

\section{EPITHELIAL DIFFERENTIATION IN DROSOPHILA: AN OVERVIEW}

\section{Development of Primary and Secondary Epithelia}

The first epithelium that emerges during Drosophila development is the blastoderm. It forms by a process known as cellularization, a modified form of cytokinesis discussed in detail below. Many epithelia in Drosophila derive from the blastoderm epithelium without a non-epithelial intermediate. Such primary epithelia, all derived from the ectoderm, include the larval and adult epidermis as well as the foregut, hindgut, Malphigian tubules, tracheae, and salivary glands. 
In contrast, secondary epithelia arise by mesenchymal-epithelial transitions later in development. Embryonic secondary epithelia are the midgut epithelium, glia sheets that form the blood-nerve barrier, and the dorsal vessel (heart). In addition to their mode of formation, primary and secondary epithelia differ in structure and mechanisms used for cell polarization $(150,154)$.

Epithelial development can be subdivided roughly into three phases in which (I) the initial establishment of polarity is (II) followed by the consolidation and elaboration of surface domains and cytoplasmic asymmetries, and finally, (III) the terminal differentiation and specialization of surface domains. For primary epithelia, phase I occurs at cellularization during which distinct membrane domains are established. Phase II extends from gastrulation throughout organogenesis and includes the formation of a CJC. Groups of epithelia behave uniformly during this phase; for example, the ectoderm and its epithelial derivatives such as the epidermis and the tracheae, all establish the same CJC. During phase III, individual epithelia undergo sometimes dramatic specializations to accommodate their anatomical or physiological function, and tissue-specific control mechanisms for epithelial differentiation become apparent. For example, the Zinc-finger transcription factor Hindsight is required to maintain the integrity of the tracheal epithelium and controls the differentiation of a specialized tracheal cuticle, which contains a characteristic spiral-shaped superstructure, the taenidium, that prevents the tracheal lumen from collapsing (177). The mechanisms that control the terminal differentiation of specialized epithelia in Drosophila remain largely elusive. In addition, because little progress has been made in understanding the polarization mechanisms of embryonic secondary epithelia since we last reviewed the subject (150), this topic is not covered here.

Models for epithelial differentiation in postembryonic development of Drosophila include the imaginal discs and the ovarian follicular epithelium (96). The larval imaginal discs are fully polarized epithelial sheets with a well-developed junctional complex comparable to the epidermis of mid-embryonic stages from which they derive. Imaginal disc epithelia lend themselves to the analysis of epithelial maintenance and terminal differentiation and specialization of epithelial surface domains. In contrast, the follicular epithelium renews itself constantly as follicle cells originate from stem cells, and allows the analysis of the full range of phases in epithelial differentiation, including epithelial formation by mesenchymal-epithelial transition and the successive assembly of a CJC. The simplicity and accessibility of the follicular epithelium together with the large number of genes known that effect its epithelial integrity make the follicular epithelium a favored genetic system to study epithelial development $(96,147)$.

\section{Cellular Junctions in Drosophila Epithelia}

The complement of cellular junctions in Drosophila epithelia comprises spot adherens junctions (SAJs), the zonula adherens (ZA), pleated and smooth septate junctions (SJs), gap junctions, and hemiadherens junctions (HAJs) (154). Early 
during development, epithelia acquire a ZA, which assembles from the coalescence of individual SAJs. HAJs and SJs form only later during epithelial differentiation. Basal HAJs (elsewhere called focal contacts) are integrin-based and connect epithelial cells to basement membranes or specialize into muscle-tendon junctions $(20,118)$. Apical HAJs are seen in cuticle-secreting epithelia connecting the apical membrane to the cuticle. SJs act as the trans-epithelial barrier in most epithelia of non-chordate animals, and thus functionally substitute for the chordate tight junction. The CJC in primary epithelia and in the follicular epithelium is composed of the ZA and the SJ. Embryonic secondary epithelia such as glia sheets and the midgut epithelium lack a ZA but contain the SJ. Desmosomes and hemidesmosomes as well as tight junctions are not seen in Drosophila epithelia. Absence of desmosomes and hemidesmosomes is corroborated by the lack of cytoplasmic intermediate filaments in Drosophila (3), and the phylogenic analysis of the cadherin superfamily that suggests that desmosomal cadherins have evolved from classic cadherins within the chordate lineage (158). Gap junctions in Drosophila and other invertebrates are formed by innexins that appear unrelated in sequence to vertebrate connexins but perform similar functions (116). From gastrulation onwards, gap junctions are ubiquitous components of epithelia (154) but their role in epithelial differentiation is currently not understood.

\section{EPITHELIUM FORMATION: CELLULARIZATION}

The formation of an epithelial sheet is typically achieved through the reorganization of a cluster of mesenchymal cells into a monolayer of tightly adhering polarized cells. Such mesenchymal-epithelial transitions are seen many times during development but are best studied in early vertebrate embryos in which a cluster of mesenchymal blastomeres forms the blastula, a hollow ball, that is bound by a blastoderm epithelium. In contrast, the formation of the blastoderm in Drosophila embryos, and most other insects takes a different route to establish an epithelium. The fertilized Drosophila egg undergoes 13 nuclear divisions that are not followed by cytokinesis. At the end of the $13^{\text {th }}$ cell cycle $\sim 5000$ nuclei form a monolayer just beneath the egg membrane. Invaginations of the egg membrane surround each nucleus and associated cytoplasm during the $14^{\text {th }}$ cell cycle, cellularizing the blastoderm and establishing an epithelium of highly columnar cells $(42-44,126)$. As cytokinesis and epithelium formation go hand in hand, the exploration of epithelial polarization of the Drosophila blastoderm provides some unique challenges.

Cellularization is initiated by the formation of the furrow canal that remains at the leading edge of the invaginating membrane (Figure 1). As cellularization proceeds, SAJs are assembled next to the furrow canal in the emerging lateral membrane $(55,97,149,154)$. These "basal junctions" (55) remain associated with the furrow canal during cellularization but resolve as cellularization is completed. Additional SAJs form as the lateral membrane grows, and concentrate apically where they will form the ZA during gastrulation $(97,149)$. A number of proteins 


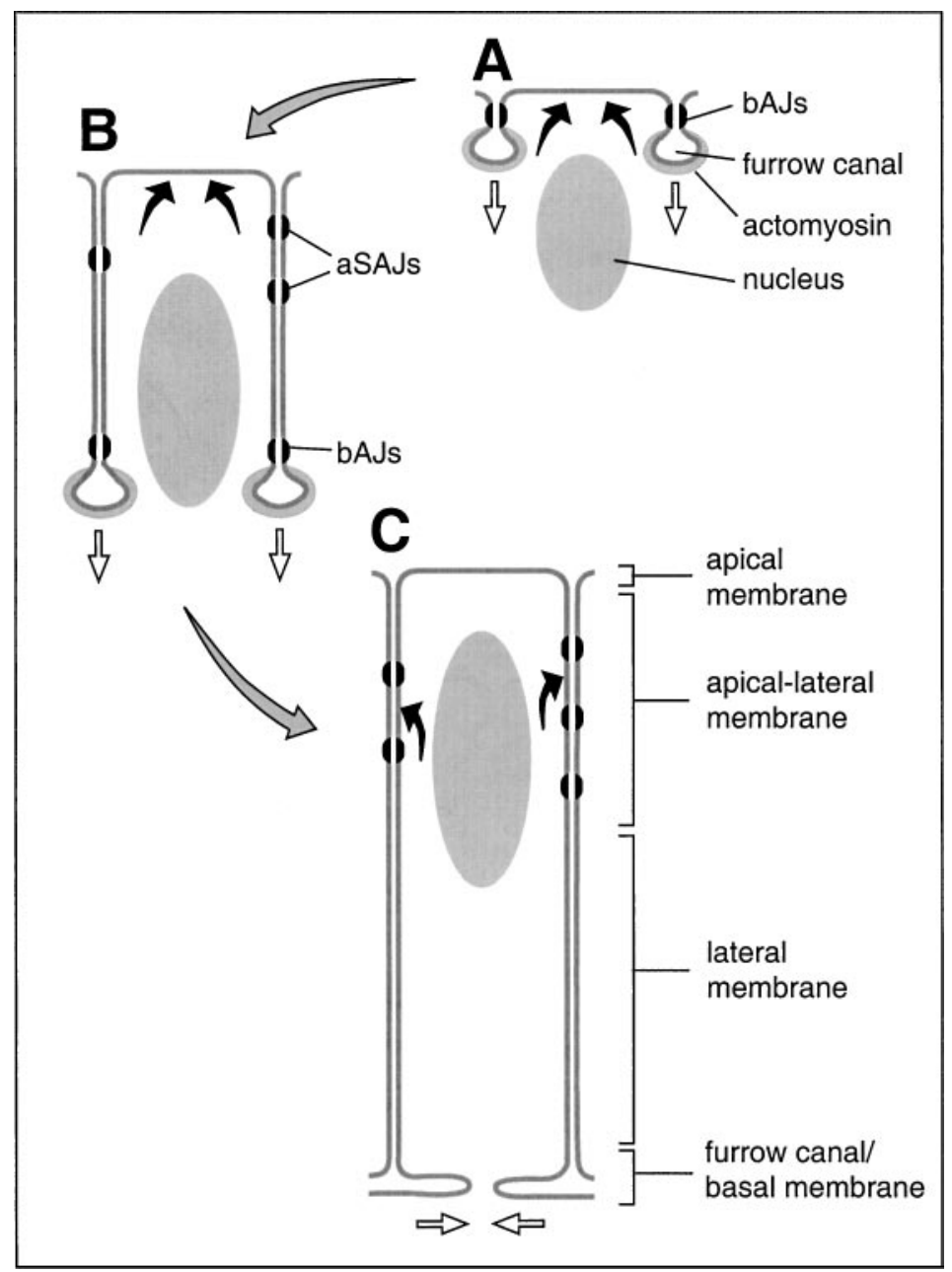

Figure 1 Cellularization forms the blastoderm epithelium in Drosophila. Three stages at early $(A)$, mid- $(B)$ and late- $(C)$ cellularization are illustrated. The open arrows indicate the direction of plasma membrane movement and the black arrows point to the main membrane insertion sites as identified in (72). (A) Invaginations of the egg membrane surround each of $\sim 5000$ nuclei and form the furrow canals. The basal adherens junctions (bAJs) remain closely linked with the furrow canals during cellularization. (B) Apical spot adherens junctions (aSAJs) form at midcellularization, increase in number and are retained in the apical one third of the lateral membrane. These SAJs will form the ZA during gastrulation. $(C)$ Four membrane domains, indicated to the right, have formed at late-cellularization. The bAJs and the actomyosin ring resolve at this time and the furrow canals expand to form the basal membrane. 
show an asymmetric distribution in the forming lateral membranes during cellularization (see below). These include the cadherin-catenin-complex (CCC) as part of the basal and the more apical SAJs $(27,55,97,149)$. Taken together, these observations suggest that a polarized lateral membrane domain is established during cellularization.

Cellularization is a modified form of cytokinesis, in which the furrow canal represents the leading edge of the cleavage furrows. As in other cells, the contractile ring of Actin and Myosin II at the furrow canal associates with Septins and Anillin during cytokinesis $(2,41,43)$. The actomyosin rings of all 5000 blastoderm cells form an interlocking hexagonal array that plays an important role in cellularization $(42,189)$. Mutations in a number of genes have been described that disrupt the actomyosin array and compromise cellularization. These genes encode factors that co-localize with the actomyosin array such as Peanut, a septin (2), Bottleneck (125), Serendipity- $\alpha$ (127), Discontinuous Actin Hexagon (191, 192), the Forminhomology protein Diaphanous (4), and possibly the small GTPases Rho1 and Cdc42 (28). Others factors that contribute to the organization or function of the actomyosin array but act at a distance include Nullo, which localizes to the basal junction $(55,117,131)$, the transcriptional regulator Lilliputian, which controls the expression of Serendipity- $\alpha$ (148), and Nuclear Fallout, a centrosome-associated protein required for recruitment of Actin and Discontinuous Actin Hexagon to the furrow canal $(123,124)$. Also Discs Lost (Dlt) localizes to the furrow canal during cellularization and, if disrupted, causes cuboidal rather than highly columnar cells to form (11).

Data from a number of systems point to a prominent role of forces generated by the insertion of new membrane in cytokinesis (53). In this model, contraction of the actomyosin ring is not the main driving force of cytokinesis but, instead, forms an elastic and tensile structure that orients and synchronizes membrane movement. For cellularization, it has now been established that at least the bulk of the membrane material required for the ingrowth of the plasma membrane is derived from the biosynthetic pathway $(21,72,132)$ and does not come from unfolding of the egg membrane, as had been proposed previously $(44,166)$. The t-SNARE Syntaxin1 (21) and the Golgi-associated protein Lava Lamp (132) are required for cellularization, and the progression of the furrow canal is blocked in response to injection of Brefeldin A, an inhibitor of Golgi-derived vesicle transport (132). The movements of vesicles and Golgi bodies from a reservoir below the nuclei into the apical cytoplasm depends on (-) end-directed microtubule transport. This vesicle movement contributes to membrane growth in particular during early cellularization $(42,43,132,172)$.

One contentious issue is the location of the site of new membrane insertion. The close association of Golgi bodies with the furrow canal (132) and the alignment of vesicles in front of the progressing furrow canal (80) suggest that the furrow canal is the primary site of membrane insertion. This scenario implies that membrane turnover in the furrow canal is rapid, with new membrane being "exported" to the growing lateral membrane. However, a recent study that traces membrane flow 
during cellularization arrives at a different conclusion (72). Labeling of glycoproteins with fluorescent wheat germ agglutinin (WGA) in live embryos shortly before or early during cellularization revealed that the successive formation of membrane domains starts with the furrow canal. The main insertion site during early cellularization is the apical membrane. WGA remains with the furrow canals as they progress inwards, and apically inserted membrane moves basally to form lateral membrane. Late during cellularization the membrane insertion site shifts to the apical part of the lateral membrane. Membrane mixing appears rather limited as WGA-labeled membrane areas remain coherent and the label does not diffuse into other membrane domains. These findings suggest a sequential establishment of membrane domains during cellularization during which the furrow canal forms first followed by the basal part of lateral membrane, the apical membrane, and finally, the apical part of lateral membrane (Figure 1). The notion that the lateral membrane is subdivided into an apical and a basal region is further supported by the asymmetric distribution of molecular markers such as Neurotactin and Spectrin $(72,161)$.

We are only beginning to unravel the mechanisms that act to establish epithelial polarity during cellularization. Distinct apical and basolateral vesicle targeting mechanisms may not contribute to the formation of the blastoderm epithelium as bulk membrane insertion from the biosynthetic pathway appears to take place first at the apical membrane and later at the apical lateral membrane (72). Cadherinbased adhesive interactions may facilitate lateral membrane formation as adherens junctions are formed as soon as lateral membranes appear. Cellularization has so far not been studied in the complete absence of the CCC. However, recent analysis of Nullo indicates that it localizes to the basal adherens junctions and is required for their formation (55). This observation suggests that this junction plays an important role as cellularization in nullo mutant embryos is highly irregular (131). In wild-type embryos, Nullo degrades prior to the formation of the apical SAJs, and prolonged expression of Nullo blocks their assembly, causing abnormalities in epithelial morphology at gastrulation (55). Taken together, these findings suggest that the novel protein Nullo differentiates between the apical and the basal part of the lateral membrane and between the adherens junctions residing in these regions. These results also indicate that the adherens junctions that form during early cellularization play an important role in the formation of the blastoderm epithelium.

\section{PROTEIN COMPLEXES INVOLVED IN SPECIFICATION AND REGIONALIZATION OF EPITHELIAL SURFACE DOMAINS}

The exploration of epithelial differentiation in Drosophila has now led to the characterization of protein complexes that regulate polarity and junctional differentiation. Pioneering genetic work has identified several genes that are required for epithelial differentiation in Drosophila, including crumbs ( $\mathrm{crb}$ ), shotgun 
(shg), bazooka (baz), stardust (sdt), lethal giant larvae (lgl), and discs large (dlg) $(19,45,61,102,175)$. The products of these genes have now been characterized, and biochemical and/or genetic data suggest that these and other proteins form complexes that associate with the plasma membrane and show a polarized distribution. These complexes give essential cues that govern the polarized organization of epithelial cells. Aside from wondering about the molecular composition and mutual interactions within each complex, we need to ask how the polarized localization of these complexes is achieved, and how the activity of each complex affects cellular organization. Figure 2 illustrates the position of cellular junctions and the distribution of protein complexes important for epithelial differentiation.

\section{Adherens Junctions and the Cadherin-Catenin Complex}

The first event after cellularization that indicates the further elaboration of the epithelial cell surface is the formation of the ZA that occurs as cellularization nears completion and gastrulation proceeds. ZA formation has been characterized as a three-step process. First, SAJs form in the lateral membrane during cellularization. Second, at the onset of gastrulation these SAJs move toward the apicolateral edge of the cells. Third, SAJs fuse into a circumferential belt, the ZA, during gastrulation $(97,149,150,154)$. At late cellularization, apical markers such as Baz and $\beta_{\text {Heavy-Spectrin }}\left(\beta_{\mathrm{H}}\right.$-Spectrin), and lateral markers such as Arm and $\beta$-Spectrin are mixed in the apical part of the lateral membrane $(97,149,161$; A. Wodarz, personal communication). The segregation of these molecules into distinct plasma membrane domains leads to the formation of apical and basolateral domains that are separated by a ZA. The apical membrane domain is subdivided into two regions at this point, the free apical surface and the marginal zone, which represents a narrow region of cell-cell contact apical to the ZA (Figure 2) (149).

The formation of SAJs during cellularization presumably depends on the CCC, although direct evidence for such a requirement is still lacking. The CCC consists of DE-cadherin, the predominant epithelial cadherin in Drosophila encoded by the shg gene, Arm, the homolog of vertebrate $\alpha$-catenin, D $\alpha$-catenin, and Dp120 ctn (103, 104, 107, 109, 152, 167; R. Cavallo \& M. Peifer, personal communication). In addition to the pool of Arm molecules that are part of the CCC, Arm is also an effector of Wingless $(\mathrm{Wg}$ ) signaling. The relation between cytosolic Arm that participates in $\mathrm{Wg}$ signaling and junctional Arm remains unresolved. The CCC is essential in the female germline and thus embryos that lack the maternal components of either DE-cadherin or Arm cannot be studied $(27,48,105,110,152,173)$ (mutations for D $\alpha$-catenin and Dp120 ctn are currently not available). However, if intermediate alleles of shg or arm are used, a limited number of fertilized eggs is recovered from females with a mutant germline. In such embryos, in which maternal and zygotic expression of $s h g$ or arm is strongly reduced, all epithelia that were examined lose integrity $(27,152)$. The development of arm mutant germline clone $\left(\mathrm{arm}^{G L C}\right)$ embryos was analyzed in detail (27). Here, plasma membraneassociated DE-cadherin is reduced and $\mathrm{D} \alpha$-catenin is not membrane associated. 


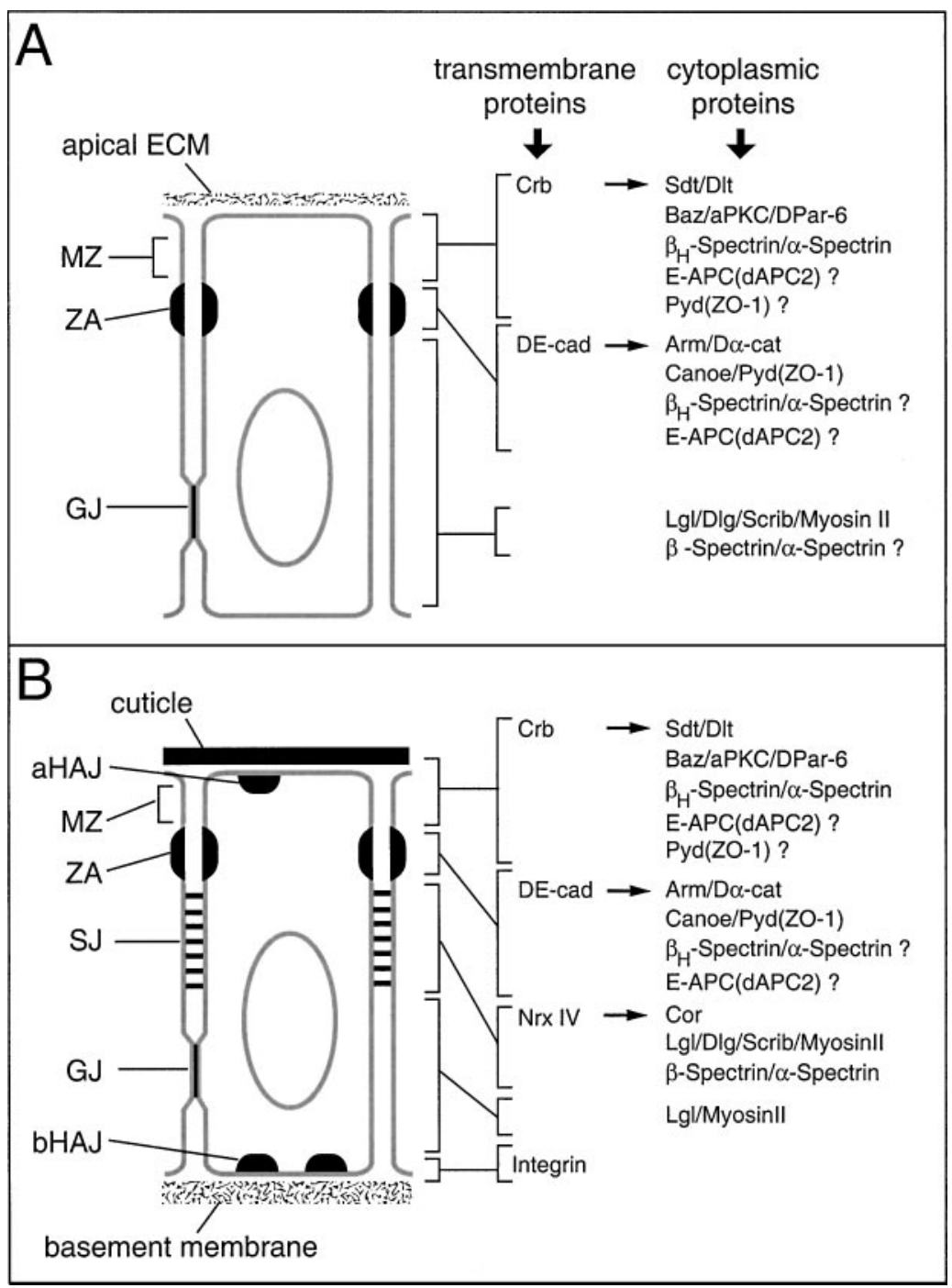

Figure 2 Schematic of epithelial cell structure in an ectodermal epithelial cell during gastrulation $(A)$ and a late-embryonic/larval epidermal cell $(B)$. Subdomains of the plasma membrane and cellular junctions are indicated to the left and the distribution of proteins discussed in this review are listed to the right. Cytoplasmic proteins that bind directly to a transmembrane protein are indicated by the small arrow. Synonyms of protein names are given in parenthesis. The question marks indicate that the localization of these proteins at the given position require confirmation, e.g., E-APC/dAPC2 might localize to the marginal zone, the zonula adherens or both regions. Abbreviations: aHAJ, apical hemi adherens junction; bHAJ, basal HAJ; DE-cad, DE-cadherin; ECM, extracellular matrix; GJ, gap junction; MZ, marginal zone; SJ, septate junction; ZA, zonula adherens. 
Nevertheless, cellularization proceeds normally in these embryos, suggesting that very limited CCC activity is sufficient to promote cellularization. Alternatively, epithelium formation during cellularization might not require the $\mathrm{CCC}$ at all. This latter interpretation is supported by the radical shift in cell morphology seen in $a^{a r m}{ }^{G L C}$ embryos at the onset of gastrulation (27). While the blastoderm forms normally in arm $^{G L C}$ embryos, epithelia rapidly acquire a multilayered mesenchymal morphology at early gastrulation. At later stages of embryonic development, the CCC is needed to maintain integrity of all epithelial tissues that were studied $(52,151-153,167)$. Thus, with the possible exception of the blastoderm, the CCC is essential to maintain adhesion and tissue architecture of Drosophila primary and secondary epithelia.

In the ovary, recent work indicates that the $\mathrm{CCC}$ is not required for the formation of the follicular epithelium but plays a role in its maintenance (147). Adherens junctions in the follicular epithelium contain DE-cadherin and DN-cadherin, which both disappear if follicle cells are rendered null for arm. arm mutant follicle cells are irregular in shape and sometimes form a multilayered epithelium. In most cases, however, arm mutant follicle cells remain within the epithelial layer and acquire a flat shape rather than being cuboidal or columnar, suggesting that the lateral membrane domain is reduced in size when the CCC is disrupted $(96,147)$. Interestingly, apical markers are lost (Crb and $\beta_{\mathrm{H}^{-}}$Spectrin) or mislocalized (Dlt) in arm mutant follicle cells although these cells retain a monolayered epithelial arrangement (147). These findings indicate that the loss of the CCC in the follicular epithelium disrupts the architecture of the apical domain without necessitating the breakdown of a monolayered epithelial tissue structure.

\section{Adherens Junctions and Cell Signaling}

Recent work in mammalian cell culture has established that the ZA, in addition to the CCC, contains a second complex composed of the immunoglobulin-like adhesion molecule Nectin and the cytoplasmic factors Afadin, a PDZ domain protein, and Ponsin, a SH3 domain protein. This complex interacts with both the CCC and the actin cytoskeleton. The knockout phenotype of Afadin in mice suggests that it has an essential role in maintaining epithelial integrity in the mouse ectoderm $(56,84,85,141,144)$. Drosophila Canoe is the apparent ortholog of Afadin. Canoe was localized at the ZA in photoreceptor cells by immunoelectron microscopy (88), and appears to be a ubiquitous component of the ZA (143). Mutational analysis of canoe did not reveal a general requirement for epithelial or ZA integrity.

canoe mutant embryos show defects in dorsal closure, an epithelial migration process regulated by Jun N-terminal kinase (JNK) and Wg signaling $(91,101,143)$. In fact, Canoe appears to be an upstream regulator of JNK signaling. In this process, Canoe colocalizes and interacts genetically and physically with Drosophila ZO-1, a MAGUK (membrane-associated guanylate kinase) protein encoded by the gene polychaetoid (previously also known as tamou) $(143,145,170)$. Moreover, analysis of the role of Canoe in imaginal development suggests that it can physically interact with Ras1 and modulate Ras and Notch signaling $(87,95,145)$. A close spatial 
association between the ZA and Ras and Notch signaling components has been described previously $(22,40,163,188)$. Taken together, next to $\mathrm{Arm} / \beta$-catenin, the work on Canoe represents the best evidence that a bona fide component of the ZA regulates cell signaling. How Canoe modulates signaling remains to be elucidated. It will also be interesting to see whether and how Canoe and Pyd/ZO-1 interact with the CCC and whether Canoe interacts with Nectin and Ponsin-like molecules in Drosophila.

In addition to $\mathrm{Arm} / \beta$-catenin, a second connection between the $\mathrm{ZA}$ and $\mathrm{Wg}$ signaling has now been made. E-APC/dAPC2, one of two Drosophila homologs of the adenomatous polyposis coli (APC) tumor suppressor, is predominantly expressed in epithelial cells and localizes to the apicolateral plasma membrane, a region that includes the ZA and the MZ $(89,187)$. Whether E-APC/dAPC2 is a component of the ZA or whether its association with the ZA is more peripheral remains to be established. Recent data from mammalian epithelial cells suggest that the majority of APC associates with the apical membrane domain and does not colocalize with the CCC at the lateral domain (120). The localization of E-APC/dAPC2 to the apicolateral region depends on the integrity of the ZA and the actin cytoskeleton $(164,187)$. The analysis of a hypomorphic E-APC/dAPC2 mutation and RNA interference experiments did not reveal overt effects on epithelial polarity, although junctional Armadillo is reduced in some tissues.

Both human APC and E-APC/dAPC2 act as part of a "destruction complex" that destabilizes Arm/ $\beta$-catenin and thus negatively regulate $\mathrm{Wg} / \mathrm{Wnt}$ signaling (111). A temperature-sensitive missense mutation in E-APC/dAPC2, $\mathrm{dAPC}^{\Delta \mathrm{S}}$, causes $\mathrm{E}-\mathrm{APC} / \mathrm{dAPC} 2$ to accumulate in the cytoplasm and compromises its role in $\mathrm{Wg}$ signaling, suggesting that the localization of E-APC/dAPC2 to the apicolateral region of the plasma membrane is essential for its signaling function (89). Interestingly, apical secretion of $\mathrm{Wg}$, which is controlled by the apical localization of its mRNA, is important for effective signaling (128), and also the Wg receptor Frizzled is a component of the apical membrane (138). The concentration of both positive and negative elements of the $\mathrm{Wg}$ signaling cascade, in addition to the components of the Notch, Ras, and JNK signaling pathways, found at the marginal zone and/or ZA suggest that this region is at the crossroad of several signaling pathways.

The ZA and E-APC/dAPC2 have now been identified as sources of a cue that controls the orientation and symmetry of cell division in the ectodermal epithelium of Drosophila embryos (82). As epithelial cells divide they round off and rise to the apical surface of the epithelium, where they remain connected to adjacent cells via the ZA (154). The spindle is oriented in parallel to the planar axis of the epithelium. Two equally sized daughter cells form that receive a similar share of apical and basolateral membrane and an equal amount of polarity determinants that associate with these membrane domains from the mother cell (82). If the ZA or E-APC/dAPC2 activity is disrupted, spindle orientation is abnormal and cell division is asymmetric (82). Two daughter cells of unequal size form, with the smaller cell receiving only basal membrane. This type of division pattern is reminiscent of mesenchymal neural progenitor cells (neuroblasts) or epithelial cells that express 
Inscutable, a key regulator of asymmetric cell division in the neuroectoderm (65). Thus, epithelial cells have the potential to divide asymmetrically. However, this potential is normally overridden by a ZA-associated cue that requires the activity of E-APC/dAPC2. Disruption of dEB1 causes similar defects as blocking of E-APC/dAPC2 activity (82). dEB1 is the Drosophila homolog of mammalian EB1 that binds to APC (139). Although dEB1 does not appear to interact physically with E-APC/dAPC2 as the latter lacks a dEB1 binding site, the phenotypic similarities suggest that both proteins interact functionally (82). EB1 is known to preferentially interact with the $(+)$ end of microtubules $(10)$. These findings raise the intriguing possibility that E-APC/dAPC2 and dEB1 may connect the ZA to the (+) end of astral microtubules during division, thereby orienting the spindle along the planar axis of the epithelium as a prerequisite of symmetric division.

\section{Apical Polarization I: The Crumbs/Stardust/Discs Lost Complex}

Aside from bona fide components of the adherens junction, the formation of the ZA depends on two protein complexes that associate with the apical membrane. The first complex is composed of Crb, Sdt, and Dlt (the Crb complex). $c r b$, which encodes an apical transmembrane protein, was the first Drosophila gene characterized as a key regulator of epithelial polarization $(155,157)$. Currently, no interaction partners are known for the 30 EGF-like and 4 LG domains found in the extracellular part of $\mathrm{Crb}$. The short cytoplasmic domain of $\mathrm{Crb}$ contains two functionally important motifs (64). One of these, the C-terminal amino acids ERLI, is a PDZ binding motif that interacts with Dlt and Sdt $(7,11,54,64)$. The physical interactions observed between $\mathrm{Crb}$ and $\mathrm{Sdt}$ are consistent with a previous genetic analysis suggesting that $s d t$ acts downstream of $c r b$ (156). Dlt contains 4 PDZ domains whereas $s d t$ gives rise to several splice forms, encoding either a MAGUK protein with a single PDZ, a SH3, and a GUK domain or a smaller protein containing only the GUK domain $(7,54)$. Crb, Dlt, and Sdt are conserved in C. elegans and mammalian species $(7,17,29,54,112$; own unpublished results). The current release of the human genome contains three $c r b$-like genes (CRB1, CRB2, CRB3) $(29,112)$. CRB1 was shown to correspond to the retinitis pigmentosa 12 (RP12) gene, mutations in which cause a degeneration of the retina (29).

As mentioned above, Dlt is found at the furrow canal during cellularization. In contrast, Crb and Sdt are first seen at the onset of gastrulation in association with the apical membrane, at which time Dlt is also recruited to the apical membrane $(7,11,54,149,157)$. How the apical localization of the Crb complex is established initially is unclear. Recruitment of Sdt and Dlt to the apical membrane depends on interactions with the cytoplasmic tail of $\mathrm{Crb}(7,11,54,64)$, whereas maintenance of apical Crb depends on Sdt and Dlt $(11,156)$. The distribution of the Crb complex within the apical domain is not uniform. Low concentrations are seen in the central region of the apical membrane, typically the "free" apical surface, whereas high levels of the Crb complex are found at the marginal zone. This accumulation of the 
Crb complex may be driven by homophilic interactions between Crb molecules on opposing cell membranes, as the localization to the marginal zone depends on the presence of $\mathrm{Crb}$ in both contacting cells (112). Crb expression persists in all epithelia that have a ZA throughout development.

The ZA is not established in $c r b$ and $s d t$ mutant embryos, and adherens junction material retains a spot-like distribution $(50,97,149)$. Failure to assemble a ZA is likely to be a major contributor to the tissue breakdown seen in mutants that are affected for a component of the Crb complex. In addition, a number of apical markers disappear from the cell surface in these mutants, suggesting that the apical surface domain is lost $(7,11,54,156,178)$. Failure to assemble adherens junctions may contribute to the loss of apical markers, as seen in the follicular epithelium (147). The Crb complex is presumably a component of a larger scaffold that controls the molecular composition of the apical membrane similar to the mutual dependencies seen between Crb complex components. In fact, $\mathrm{Crb}$ is sufficient to promote apical membrane differentiation as Crb overexpression results in an apicalization of the cell surface at the expense of the basolateral membrane and a complete disruption of the CJC $(50,179)$. Overexpression of the membrane-tethered cytoplasmic domain of $\mathrm{Crb}$ can rescue the $c r b$ mutant phenotype and cause membrane apicalization to a similar degree as overexpression of full-length Crb (179). The C-terminal PDZ binding motif in the cytoplasmic domain of Crb is essential for this activity (64). In contrast, overexpression of Dlt does not cause an apicalization phenotype (11; G.T. \& U.T. unpublished data), whereas overexpression of Sdt still needs to be examined.

A functional overlap between Crb activity and other polarization mechanisms becomes apparent when the effects of $c r b$ mutations on different epithelial tissues that express $\mathrm{Crb}$ at similar levels and with similar subcellular distributions are compared. While the disruption of the ZA is uniform throughout ectodermal and endodermal epithelia during gastrulation $(50,149)$, tissue-specific responses to the lack of $\mathrm{Crb}$ or Sdt become apparent when individual organ primordia are established $(155,156)$. The epidermis is most strongly affected, and the great majority of cells die through programmed cell death. On the other extreme, there are tissues that appear more or less normal in late mutant embryos such as the Malphigian tubules or parts of the foregut and hindgut, implying that these cells were able to recover and establish normal polarity and a CJC although their ZA did not form during gastrulation (155-157). In fact, if epidermal cell death is prevented, surviving cells form small epithelial vesicles in which individual cells show normal polarity and possess a CJC (G.T. \& U.T. unpublished data). Thus, it appears that Crb is required to establish normal polarity at early stages but is not needed to maintain epithelial polarity at later stages of development. Moreover, epithelial development in $c r b$ null mutants can be rescued to a large extent by increasing the wild-type gene copy number of $s d t$ from two to three, suggesting that Sdt has a Crb independent apicalization activity (156). Further, in $c r b$ null mutant cells that do not die, Dlt is reduced but not lost entirely from the apical membrane, suggesting that a Crb-independent apical targeting mechanism must exist for Dlt that may partially or completely compensate for the loss of Crb (147). Taken together, 
these observations hint at complexities in the organization of protein scaffolds that define the apical surface domain of epithelial cells that remain largely elusive.

\section{Apical Polarization II: The Bazooka/aPKC/DPar-6 Complex}

A second complex that is important for the formation of the ZA but not a ZA component is composed of Bazooka (Baz), the Drosophila homolog of C. elegans Par-3 and vertebrate ASIP (66), Drosophila Par-6 (DPar-6) (115), and the Drosophila homolog of atypical Protein Kinase C (DaPKC) (180). This complex, called here the Baz/Par-3 complex, is conserved in C. elegans embryos where it contributes to the asymmetric division of the egg (122). In Xenopus oocytes this complex associates with the animal pole during maturation (99), and it localizes to tight junctions in mammalian epithelial cells where it is required for normal cell polarization $(57-59,78,119,140)$. Moreover, recent work in cell culture and $C$. elegans has shown that the small Rho family GTPases Cdc42 or Rac1 interact in their active, GTP-bound state with Par- 6 and control localization and activity of the Par-3/Par-6/aPKC complex (49, 58, 59, 63, 78, 119).

Embryos that lack Baz function show defects at late cellularization/early gastrulation, at which time SAJs fail to concentrate at the apex of blastoderm cells and do not form a ZA (97). At early gastrulation in these mutant embryos, epithelial cells lose polarity, acquire mesenchymal characteristics, and gastrulation movements are compromised as a consequence. Later in development most cells die by programmed cell death $(97,174$; U.T. unpublished data). This phenotype is very similar to the phenotype seen in $\mathrm{arm}^{G L C}$ mutants, suggesting that the failure of ZA assembly may be the major consequence of lack of Baz function. A similar phenotype is seen in embryos that lack DaPKC (180), whereas embryos that lack DPar-6 appear to undergo gastrulation movements normally and then subsequently lose epithelial integrity (115). Although the interactions between Cdc42 and the Baz/Par-3 complex have not been studied so far, embryos with reduced Cdc42 activity show defects in epithelial differentiation related to those in embryos with reduced activity of the Baz/Par-3 complex (46), raising the possibility that Cdc42 interacts with this complex as seen in other systems. The Baz/Par-3 complex associates with the entire apical membrane but is concentrated at the marginal zone similar to the Crb complex (180). It remains unclear as to how the Baz/Par-3 complex is linked to the plasma membrane, how it controls ZA assembly, and whether it has other important roles in epithelial polarity, in addition to ZA formation.

\section{Apical Polarization III: The Lethal Giant Larvae/Discs Large/Scribble Complex}

Molecular integrity and size of the apical domain also relies on the function of lateral protein complexes. Disruption of the CCC leads to loss of Crb and other factors from the apical membrane as mentioned above. A second interacting group of proteins that was recently implicated in the control of apical polarization is composed of Lgl, Dlg, and Scribble (Scrib) (14). Lgl is a Myosin II binding protein that contains WD40 repeats $(93,135)$, whereas Dlg and Scrib are multi-PDZ 
domain proteins; Dlg is a MAGUK (183) and Scrib belongs to the LAP subfamily of PDZ domain proteins that also contain leucine-rich repeats $(13,15) . l g l, d l g$, and scrib mutants display similar defects in the embryo, imaginal discs, and the follicular epithelium. In addition, colocalization and genetic interactions observed between these genes suggest that these proteins may form a biochemical complex, called here the Lgl complex (14). Lgl, Dlg, and Scrib homologs are found in $C$. elegans and vertebrates where they play a role in epithelial polarization as well $(16,17,75,91 \mathrm{a})$. Also the $\mathrm{Lgl}$ homologs in yeast and humans have been shown to interact with Myosin II $(62,137)$, suggesting that $\mathrm{Lgl}$ may regulate Myosin II function. In fact, suppression of myosin II function by Lgl has recently been demonstarted in Drosophila neuroblast where Lgl and Dlg control neuroblast polarity during asymmetric division $(106,113)$.

$l g l$ and $d l g$ were identified as tumor suppressor genes that control proliferation and tissue integrity of imaginal discs $(45,93,183)$. In imaginal discs and in late embryos, Dlg and Scrib are specific components of the SJ, whereas Lgl overlaps with the SJ but retains a broader distribution at the basolateral membrane $(14,15,136,183,184)$. The role of the $\mathrm{Lgl}$ complex as a component of the SJ is discussed in more detail below. Defects in epithelial polarity in $l g l, d l g$, or $s c r i b$ mutant embryos, which lack both maternal and zygotic expression of these genes, or mutant follicular epithelia appear long before $S J$ form $(14,15,114)$. Cells of the ectodermal epithelium show a mislocalization of apical markers, such as $\mathrm{Crb}$, and ZA markers, such as Arm. Both apical and ZA markers spread basally, suggesting that the marginal zone and the ZA do not form normally and the apical membrane expands basolaterally $(14,15)$. These defects are most prominent during gastrulation, whereas at later stages of development normal polarity is re-established and a normal CJC forms (G.T. \& U.T. unpublished data). These findings suggest that the $\mathrm{Lgl}$ complex controls the segregation of apical and basolateral membrane domains at gastrulation and contributes to confinement of apical and apico-lateral markers to their normal position. How the Lgl complex acts to support normal differentiation of epithelial surface domains is unclear at present. As mentioned, the link to Myosin II may suggest that the regulation of Myosin activity is one target of the Lgl complex also in epithelial cells. Alternatively, the recent finding that the yeast homolog of $\mathrm{Lgl}$ interacts with a SNARE protein in polarized vesicle targeting (76) raises the possibility that the Lgl complex may regulate vesicle targeting to control epithelial polarity. This notion is also supported by the finding that a human Scrib homolog, ERBIN, restricts the ERBB2/HER2 receptor to the basolateral membrane (16).

\section{THE SEPTATE JUNCTION}

\section{Structure and Functions of Septate Junctions}

One of the most distinctive ultrastructural features of the CJC in invertebrate epithelial cells is the SJ. During Drosophila development, SJs first appear midway 
through embryogenesis, well after cellularization is completed, epithelial polarity has been established, and the ZA has formed. The SJ lies just basal to the ZA in epithelial cells, and within the SJ the membranes of adjacent cells maintain a constant distance of approximately $15 \mathrm{~nm}$. In the pleated SJ (found in ectodermally derived epithelia and the glia sheets), regular arrays of electron-dense septae span the intermembranal space. In addition, freeze-fracture analysis reveals the presence of parallel rows of intramembranal particles $(100 \mathrm{a}, 171)$ that presumably represent transmembrane proteins within the SJ. The septae form circumferential spirals around the cell much like the threads of a screw, and thereby greatly increase the distance that molecules must travel to pass between the apical and basolateral compartments of the epithelial sheet (25). Smooth SJs, which lack these ladderlike structures, are found only in the midgut and its derivatives. Relatively little is known of this variant of the SJ and for this reason we concentrate on the pleated $\mathrm{SJ}$ in this review.

Like other intercellular junctions, SJs have been proposed to play a role in formation of a trans-epithelial diffusion barrier, establishing and/or maintaining cell polarity, cell adhesion, and mediating interactions between cells. A variety of observations have led to the suggestion that SJs function in the formation of a trans-epithelial barrier. Morphological analysis, which revealed the existence of septae that fill the space between cells, led to the suggestion that SJs function to block direct paracellular flow between the apical and basolateral surfaces of epithelial sheets. This hypothesis was confirmed using injection of electron-dense dyes, which show restriction of dye diffusion at the SJ (25). More recently, mutational analysis of genes that encode SJ components has shown that disruption of the intercellular septae also results in disruption of the transepithelial seal $(8,68)$. A similar function has been ascribed to tight junctions in vertebrate epithelia, though SJs are quite different from tight junctions both morphologically and molecularly. Recent studies show that tight junctions regulate paracellular $\mathrm{Na}^{+}$and $\mathrm{Mg}^{++}$ion flow by means of a selective "channel" function (129). Whether SJs display a similar ability to selectively regulate paracellular flow is a question that remains to be answered.

In addition to creating the paracellular barrier in ectodermally derived epithelia, pleated SJs have an essential role in the formation of the blood-nerve barrier in insect nervous systems (25). Although insect neurons are not myelinated as they are in vertebrates, neurons are typically surrounded by perineurial and glial sheath cells that form a diffusional barrier between the neurons of the central or peripheral nervous systems and the surrounding hemolymph. In some insects, though not in Drosophila, tight junction-like structures have been identified, in addition to SJs, in the surrounding cells $(25,70)$. Specific evidence regarding tight junctions in insects is discussed in a later section. All available evidence suggests that the SJs in epithelial cells and those in ensheathing perineurial and glia sheets are essentially indistinguishable.

Because SJs appear developmentally well after the time that epithelial polarity is established, they do not seem to be directly involved in this process, though they could be required to maintain that polarity once established. Thus the relationship 
between the SJ and apical-basal polarity is currently unclear. Mutations in some known SJ components disrupt the structure of the junction and the localization of other SJ components, but do not seem to affect the ZA, transmembrane proteins such as Notch, or apically localized components of the cytoskeleton (68). These observations suggest that SJs do not function as a fence that blocks diffusion of membrane components between the apical and basolateral surfaces. However, previous experiments have indicated that such a fence does exist in invertebrate epithelia that lack tight junctions, though the SJ was not directly shown to be the source of the fence function (181). In addition, mutations in other known SJ-associated proteins, notably $l g l, d l g$ and $s c r i b$, do affect epithelial polarity (see earlier discussion). These seemingly contradictory results may indicate that the SJ has a selective fence function for particular proteins and that a mutation in one component may affect only a subset of apically or basally localized proteins. Alternatively, the early function of the Lgl complex in cell polarity may be distinct from its later role at the SJ.

\section{Molecular Architecture of the Septate Junction}

Although no systematic attempt has been made yet to characterize the molecular components of the SJ, molecular genetic analysis of several developmentally interesting genes has led to the discovery of SJ components. Of the SJ-associated proteins thus far identified, two, Coracle (Cor) and Neurexin-IV (Nrx-IV), appear to be most central to the morphologically defined SJ. Cor is a member of the Protein 4.1 superfamily of cytoplasmic proteins (39) that includes Protein 4.1, the Ezrin, Radixin, and Moesin (ERM) proteins, the NF2 tumor suppressor Merlin, Talin, several protein tyrosine phosphatases, unconventional myosins, and Drosophila Expanded (146). Cor is most similar to Protein 4.1, showing approximately $60 \%$ identity with Protein 4.1 in the amino-terminal 400 amino acids, a region of the molecule that is highly conserved in all members of the superfamily. This domain has been termed the FERM domain (26). In Cor, this domain appears to provide all functions that are required for localization to the SJ (168), as well as for SJ structure and function (169). Cor also shares a region of similarity with Protein 4.1 at the carboxy terminus that is not required for SJ function but is essential for viability. Phenotypic analysis of cor mutants revealed a role for cor during dorsal closure, salivary gland morphogenesis, and cuticle formation during embryonic development $(39,68,168)$.

Examination of a null cor allele demonstrated a requirement for Cor in the formation of the SJ (68). cor mutant embryos lack the intercellular septae that are characteristic of the pleated SJ. The functional significance of this observed defect was tested by examining permeability of a $10-\mathrm{kD}$ rhodamine-labeled dextran in living embryos. Dextran injected into the hemocoel of cor mutant embryos freely crosses the salivary gland epithelium, whereas in wild-type embryos injected in a similar manner dye cannot cross the epithelial barrier for at least one hour. Thus, cor function is clearly required for the trans-epithelial barrier function of the SJ, 
although, as noted previously, cor is not required for overall epithelial polarity or to restrict cell proliferation.

A significant step in understanding the role of Cor in SJ function was made with the discovery of the Nrx-IV gene (8). Nrx-IV is a Drosophila member of the Caspr (Contactin associated protein) family of neuronal receptors, which have a large extracellular domain with EGF and LG domains, and a single discoidin-like domain. Drosophila Nrx-IV possesses a single membrane-spanning region and, of particular interest, a short cytoplasmic domain that displays greater than $60 \%$ similarity to the cytoplasmic domain of glycophorin $\mathrm{C}$, a transmembrane binding partner for Protein 4.1 in the erythrocyte (5). Like Cor, Nrx-IV is expressed in all cells that produce SJs, and its expression profile and subcellular localization are almost indistinguishable from that of Cor $(8,168)$.

$N r x-I V$ mutants display dorsal closure defects similar to those in cor and $d l g$ mutant embryos $(8,168)$. Ultrastructural analysis revealed that the $\mathrm{SJ}$ is disrupted in Nrx-IV mutant embryos just as it is in cor mutants, identifying Nrx-IV as an important structural component of the SJ. Nrx-IV mutant embryos also display paralysis due to a breakdown of the blood-nerve barrier. Because this barrier is thought to be maintained by SJs, this result suggests that Nrx-IV, like Cor, is necessary for the barrier function of the SJ. Interestingly, mutations in Drosophila gliotactin, which encodes a neuroligin-like protein, also disrupt the blood-nerve barrier $(6,47)$. Neuroligins were originally identified as ligands for neurexins in neuronal synapses (23). Thus, it is possible that Gliotactin functions as a ligand for Nrx-IV in the SJ.

The similarity between the cytoplasmic tail of Nrx-IV and glycophorin C, the colocalization of Nrx-IV and Cor in the SJ, and the similarity of cor and Nrx-IV mutant phenotypes all suggest that cor and Nrx-IV may physically and functionally interact. Consistent with this notion, in $N r x-I V$ mutant embryos Cor fails to localize to the SJ and instead is distributed along the plasma membrane and in the cytoplasm $(8,168)$. Conversely, loss of cor function also affects Nrx-IV subcellular localization. Further studies have also shown that Cor and Nrx-IV can be co-immunoprecipitated from cell extracts, and that these proteins bind directly via the N-terminal conserved domain of Cor and the cytoplasmic tail of Nrx-IV (168). An unresolved question is how Cor and Nrx-IV initially target to the SJ, since they appear to show an interdependence that is incompatible with either one of them having this role. This observation suggests that at least one other protein whose identity is not yet known must be involved. By analogy with Protein 4.1 and glycophorin $\mathrm{C}$, which interact with the PDZ domain containing proteins hDLG and p55 $(83,86)$, this third protein likely contains PDZ domains. The obvious candidate for this role is Dlg, but attempts to identify interactions between Dlg and either Cor or Nrx-IV have thus far produced negative results (168).

As indicated earlier, Dlg is another $\mathrm{SJ}$-associated protein, and in fact was the first protein shown to localize preferentially to the SJ (183). Dlg is initially uniformly distributed along the lateral membrane and to a lesser extent throughout 
the cytoplasm. During mid-embryogenesis, this subcellular localization is refined to the presumptive SJ (183). Although the precise cellular function of Dlg in the SJ is not known, previous work has demonstrated a direct role for $\mathrm{dlg}$ in the ultrastructure and function of the SJ (184). Imaginal discs in $d l g$ mutant larvae lack the septae that characterize the pleated SJ, whereas some ZA material is mislocalized to a more basal location. In addition, the apical-basal polarity of the imaginal tissues is disrupted in $d l g$ mutants. Interestingly, these effects are less severe in the nondividing salivary gland epithelial cells, perhaps suggesting that the SJ can be maintained once established, at least in cells that are not mitotically active, and therefore are not disassembling and reassembling the CJC.

$d l g$ mutant imaginal discs display loss of epithelial polarity, cellular apoptosis, and overproliferation that becomes apparent during the extended larval period (more than twice the normal length) that is a consequence of this mutation $(1,182)$. As described previously, Dlg is part of the Lgl complex that is essential for epithelial polarity in the early embryo (14). The core function of this complex is likely the same in early embryogenesis, before the SJ forms, and later when the complex is associated with the SJ. Less clear is how the function of these proteins relates to the structure of the SJ itself. One possibility is that Dlg, Scrib, and Lgl, cooperatively, establish a unique domain in the apical lateral membrane that serves as a scaffold upon which the later-acting SJ components, such as Cor and Nrx-IV, can assemble during the formation of the SJ.

In addition to their effects on epithelial polarity, mutations in $d l g, l g l$, and $s c r i b$ also result in tumor-like overgrowth of imaginal epithelia. However, because null mutations in these genes also affect the formation of other junctions, it is unclear if the observed overproliferation effect results from a direct role in restricting cell proliferation, or instead from disruption of intercellular interactions. In contrast to the overproliferation phenotypes of $l g l, d l g$, and scrib, mutations in cor result in a decreased rate of cell proliferation and eventual loss of cells from the epithelium due to cell competition (68). In addition, cor mutations dominantly suppress the hypermorphic Ellipse allele of the EGF receptor gene (39). Unlike $d l g$, scrib, and $l g l$, cor mutations do not affect overall epithelial polarity or the ZA. This result could suggest that some aspect of SJ function is required to promote cell proliferation, whereas disruption of apical-basal polarity and CJC formation results in overproliferation, perhaps due to the loss of intercellular interactions that normally function to restrict proliferation.

\section{Relationship between the Insect Epithelial and the Vertebrate Paranodal Septate Junction}

Until recently, septate junctions were believed to be unique to invertebrates, unlike the ZA, which appears to be widespread throughout the metazoans. However, it is now apparent that within the vertebrate nervous system a structurally 
and functionally analogous SJ exists. Paranodal SJs are found in myelinated neurons at either end of each node of Ranvier, the region between adjacent sections of the myelin sheath in which components necessary for the action potential (primarily the voltage gated $\mathrm{Na}^{+}$channel) are clustered (Figure 3). These SJs form between the loops of myelinating oligodendrocytes and Schwann cells and the axons they ensheath. Morphologically, paranodal SJs are quite similar to SJs found in insect epithelial cells and glia, displaying a characteristic array of ladder-like cross-bridges $(9,108,176)$. Functionally, paranodal SJs are thought to provide insulation between the nodal and internodal regions of the axon, thereby allowing the saltatory conduction that is essential for rapid transmission of electrical signals along myelinated nerve fibers. In addition, as the primary site of contact between axons and glia, they are almost certainly important in mediating signals between these very different but closely interlinked cell types.

Recent studies have made significant progress in understanding the molecular composition and genetic functions of the paranodal SJ. One of the first identified components of this junction, Caspr (Contactin-associated protein; also known as Paranodin), is the mammalian homologue of Drosophila Nrx-IV. Caspr is expressed only in neurons, and in mature myelinated neurons it is found exclusively in the paranodal SJs $(36,94)$. Caspr binds to a neuronal isoform of Protein 4.1 via its cytoplasmic tail (94), just as Nrx-IV binds to Cor (168). Thus two primary components of the invertebrate SJ have homologous counterparts in the vertebrate paranodal SJ. As its name implies, Caspr was isolated via its association with Contactin, a GPI-linked protein that is also expressed by neurons and localizes to the paranodal SJ. In addition to binding Caspr (in cis within the neuronal membrane), Contactin colocalizes with Neurofascin-155, an immunoglobulin superfamily adhesion molecule that is expressed on myelinating glia cells, although they do not appear to interact directly (142).

The functions of two components of the paranodal SJ, Caspr and Contactin, have recently been examined using knockout mutations in the mouse $(12,18)$. Mutation of either gene results in dramatic disruption of paranodal architecture and junctional function. As expected, both mutations alter the electrical properties of myelinated nerve fibers, resulting in reduced conduction velocity along the nerve. More surprising is the effect of these mutations on the organization of other proteins within the node of Ranvier, the paranodal regions, and in the myelinating cells. In Caspr knockout mice, the paranodal localizations of Contactin in the neuron and Neurofascin-155 in the myelinating cells are disrupted (12). Furthermore, $\mathrm{Na}^{+}$channels that are normally restricted to the node spread laterally along the axon into the paranodal region. Conversely, in Caspr mutant mice neuronal $\mathrm{K}^{+}$channels that normally are found just outside the paranodal region (in the juxtaparanode) redistribute into the paranodal region and into the node itself. Similar effects, including abnormal localizations of Neurofascin- 155 and $\mathrm{K}^{+}$channels, are seen in the contactin knockout mutant (18). In addition, Caspr protein failed to be transported from the neuronal cell body to the axon in contactin mutant neurons, consistent with previous reports 
that these proteins form a complex prior to transport to the plasma membrane (37).

Taken together, these results provide strong evidence that the paranodal SJ not only provides a site of contact between the neuron and myelinating glia cell, but also serves as a molecular sieve that organizes the nodal, paranodal, and juxtaparanodal regions of myelinated neurons (108). This sieving effect appears to be analogous to the fence function within the plane of the plasma membrane that has

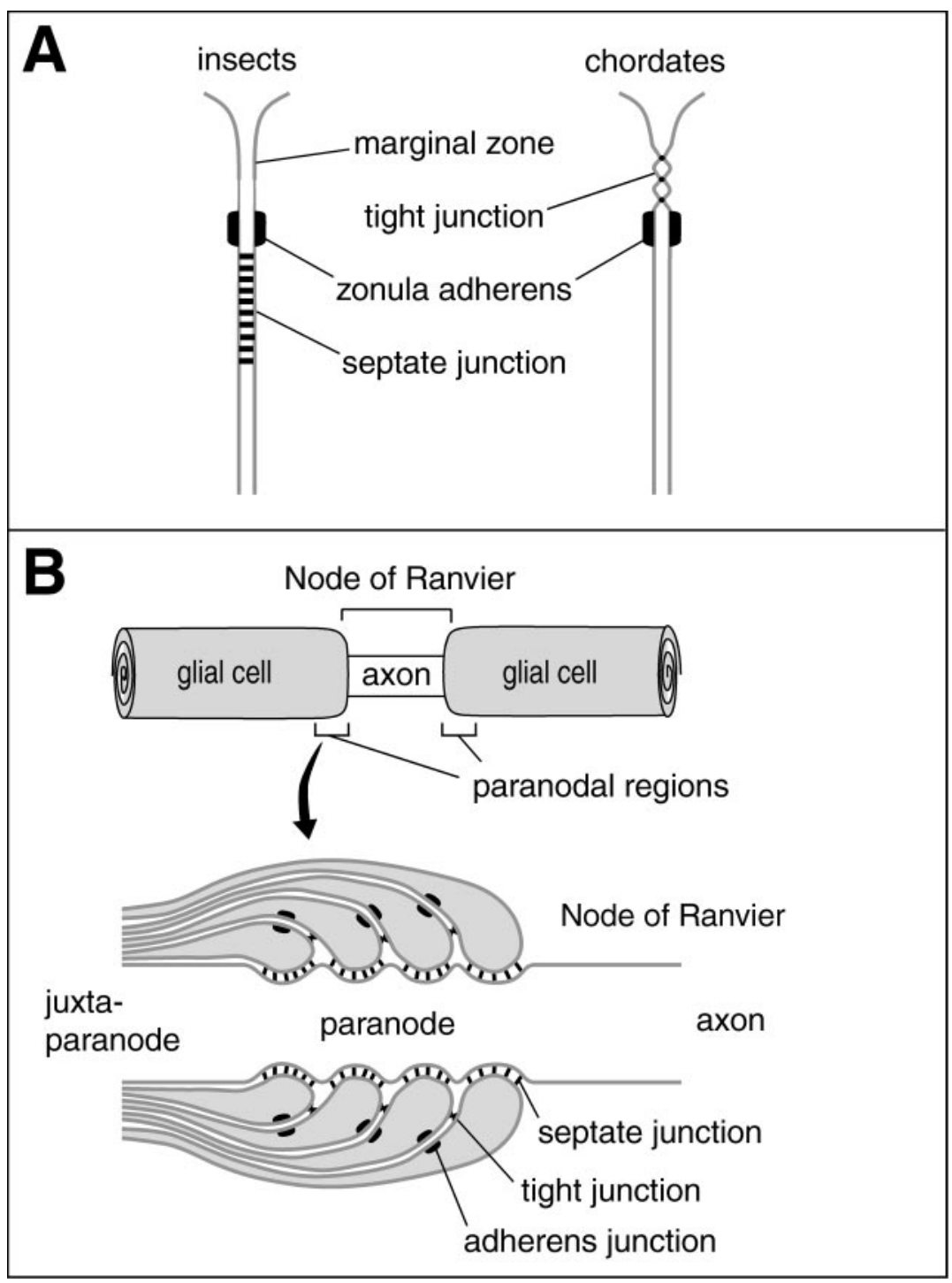


been shown for tight junctions in mammalian epithelial cells (133) and proposed for the SJ in invertebrate epithelia (181). Given their molecular and morphological similarities, the invertebrate SJ and the mammalian paranodal SJ probably both derive from a common ancestral junction and they are both structurally and functionally homologous. This observation has important implications for both SJs. By analogy with the paranodal SJ, epithelial SJ may have a selective fence function within the plane of the plasma membrane that has not yet been well characterized, and an as yet unidentified Contactin-like molecule may serve as a binding partner for Nrx-IV. Conversely, genetic studies of the epithelial SJ and epithelial polarity in Drosophila should provide new insights into the components and functions of the paranodal SJ in vertebrates. For example, we currently know little about the mammalian homologues of $l g l$, scrib, and $d l g$ in neuronal development; however, the localization of these proteins to the epithelial SJ and their importance in epithelial polarity and SJ function suggest that their mammalian homologues are significant components of paranodal SJs and axonal cell polarity.

\section{TIGHT JUNCTIONS IN DROSOPHILA?}

As mentioned earlier, in vertebrate epithelia tight junctions are believed to form the principle paracellular barrier to transepithelial diffusion. Morphologically, tight junctions are characterized by strands of intramembranous particles in freeze fracture analysis. Based on this criterion, previous studies have reported the existence of tight junctions in a variety of invertebrate species, including insects (25, 69-71). However, careful morphological studies have so far failed to identify a tight junction-like structure in Drosophila $(25,154)$. For this reason, and because the SJ seems to provide at least some of the functions ascribed to tight junctions in vertebrate cells, there has not been a clear consensus on the existence of tight

Figure 3 Comparison of Drosophila and chordate apical junctional complexes (A) and the structure of the vertebrate paranodal junction $(B)$. Insect and chordate epithelia are similar in that the junctional complex in both contains a zonula adherens. In insects the marginal zone is apical to the zonula adherens, whereas in chordates the tight junction is located at this position. Insect epithelial cells have in addition a septate junction that lies basal to the zonula adherens. In $(B)$, the structure of the node of Ranvier in myelinated neurons is diagrammed above, with a higher magnification view of the paranodal region presented below. In the node of Ranvier, the myelin sheath is interrupted. At the edge of the sheath (the paranodal region) loops from the myelinating cell are closely apposed to the axon. At the point of contact between the neuron and the myelinating cell, a septate junction forms that is structurally and molecularly similar to the septate junction of insect epithelial and glial cells. 
junctions in insects, nor have any functional studies been performed in Drosophila.

Despite the lack of evidence for tight junctions in Drosophila, molecular genetic analysis of developmentally important genes and the Drosophila genome project have identified apparent homologues of known components of the vertebrate tight junction. For example, the previously mentioned $p y d$ gene encodes a protein that is similar to the mammalian ZO-1 protein, the first identified tight junction component $(134,145)$. Although PYD/ZO-1 was originally described as an SJ component, subsequent studies indicate that one isoform is localized apical to the SJ, while another seems more broadly distributed in the apical region of the cell (170). Analysis of vertebrate tight junctions has identified two other types of proteins that seem to be integral to the tight junction, the occludins and the claudins, although recent studies indicate that only the claudins are essential for tight junction function (165). The Drosophila genome does not contain any convincing occludin homologues (3). In contrast, there are at least two possible claudin-like genes in the genomic sequence (CG3770 and CG6982) that have four predicted transmembrane domains in a similar arrangement to the claudins (R. Fehon, unpublished observations). So far, neither of these predicted genes nor the proteins they encode have been studied.

Why then have tight junctions not been observed in Drosophila? Note that although PYD/ZO-1 is expressed apically in epithelial cells (170), we do not yet know how widely the claudin-like proteins are expressed. Thus, Drosophila tight junctions might be restricted to a particular developmental stage or tissue that has not been examined carefully enough to detect tight junctions (24). However, Drosophila epithelia might also retain some tight junctional structure, at least at the molecular level, but not have the occluding function of the mammalian tight junction (that is instead provided by the SJ). In mammalian epithelia, the tight junction is found at the apical-most point of contact between cells, just apical to the ZA. In Drosophila, the corresponding region is the marginal zone (149) (Figure 3), an area that lacks obvious junctional morphology but does seem to have an accumulation of transmembrane receptors and associated proteins $(7,11,54,66,115,149,170,180)$. Of particular interest in this regard is the recent demonstration that the Baz/Par-3 complex, which localizes to the marginal zone $(66,115,180)$, has mammalian homologues that reside in the tight junction and is essential for tight junction assembly $(57,58$; also see earlier discussion of these genes). Taken together, these results indicate that a number of tight junction proteins localize to the marginal zone in Drosophila, whereas currently no Drosophila homologues of tight junction proteins are known that associate with the SJ. These data suggest that the marginal zone in Drosophila epithelia may share some functions, in particular cell-cell signaling and perhaps the fence function within the plane of the plasma membrane, with the mammalian tight junction. In this regard it would be particularly interesting to know the subcellular localizations of the claudin-like proteins in Drosophila epithelial cells, if indeed they are expressed in these tissues. 


\section{THE SPECTRIN CYTOSKELETON IN EPITHELIAL DIFFERENTIATION}

One important aspect of epithelial polarity is the corresponding polarization of the underlying actin-based cytoskeleton that occurs via interactions between polarized transmembrane proteins, membrane-associated cytoplasmic proteins, and cytoskeletal proteins $(100,185)$. Among the many proteins that appear to be involved in this process, spectrin seems to play a crucial role. The spectrin protein is a tetrameric actin crosslinking protein comprised of two $\alpha$ and two $\beta$ subunits. Epithelial cells contain a polarized spectrin cytoskeleton, in which distinct isoforms of spectrin associate with the apical or basolateral membrane. Spectrin contributes to polarized membrane organization by binding, and thus trapping membrane proteins at the basolateral surface $(92,100)$.

Drosophila has three different spectrin subunits, $\alpha, \beta$, and $\beta_{\mathrm{H}^{-}}$Spectrin, which assemble into two different isoforms, $\alpha_{2} \beta_{2}$-Spectrin and $\alpha_{2} \beta_{\mathrm{H} 2}$-Spectrin. $(32,159)$. The two isoforms show non-overlapping polarized distributions in epithelial cells. $\alpha_{2} \beta_{2}$-Spectrin is found at the basolateral membrane where it forms a complex with Ankyrin $(33,35,74)$. In contrast, the $\alpha_{2} \beta_{\mathrm{H} 2}$-Spectrin associates with the apical domain where it is enriched in the marginal zone and, possibly, the ZA $(160,162)$ (Figure 2). Before the onset of cellularization, $\alpha_{2} \beta_{\mathrm{H} 2}$-Spectrin associates with the egg membrane, and during cellularization it remains with the furrow canals, whereas $\alpha_{2} \beta_{2}$-Spectrin is added to the lateral membrane as it forms. At late cellularization, $\beta$-Spectrin and $\beta_{\mathrm{H}^{-}}$Spectrin overlap in the apical-lateral membrane, as mentioned above, before they segregate into their final distinct apical and basolateral positions (161).

Mutational analyses have been carried out for all three Drosophila spectrin genes but so far did not reveal a general role of the spectrin cytoskeleton in epithelial polarity. Lack of $\beta_{\mathrm{H}^{-}}$Spectrin does not cause defects in cellularization or epithelial polarity in early embryos (J.A. Williams \& G.H. Thomas, personal communication), whereas the requirement of $\beta$ - and $\alpha$-Spectrin in early embryos remains to be analyzed. However, spectrin mutants exhibit a number of interesting defects, which suggest that spectrin has cell type-specific roles in epithelial differentiation. $\alpha$-spectrin mutants die as larvae and exhibit loss of cell-cell contacts in the midgut whereas other epithelial tissues differentiate normally (74). $\alpha$-spectrin mutations affect the cuprophilic cells of the midgut epithelium that are responsible for the acidification of the midgut content. In $\alpha$-spectrin mutant larvae, $\beta_{\mathrm{H}^{-}}$Spectrin is lost from the apical membrane of cuprophilic cells. In addition, the actin cytoskeleton appears disorganized, and acid secretion is impaired $(31,74)$. In contrast, cuprophilic cells mutant for $\beta$-spectrin show a disrupted organization of the basolateral membrane that fails to accumulate the $\mathrm{Na}^{+}, \mathrm{K}^{+}$-ATPase, a defect not seen in $\alpha$-spectrin mutants (34). These findings suggest that $\alpha_{2} \beta_{\mathrm{H} 2}$-Spectrin is required for the differentiation of the apical membrane in cuprophilic cells, and that $\beta$-Spectrin functions independently of $\alpha$-Spectrin in the differentiation of the basolateral membrane domain. 
$\beta_{\mathrm{H}^{-}}$Spectrin in encoded by the karst gene. karst mutations are semiviable and adult escapers exhibit bent wings, tracheal defects, sterility, and rough eyes (162). However, no obvious polarity defects were observed in karst mutant imaginal discs. A role for spectrin in the maintenance of epithelial polarity has been found in the ovarian follicular epithelium (73). Follicle cells that lack $\alpha$-Spectrin form a normal follicular epithelium initially, but exhibit overproliferation, multilayering, and loss of the apical $\beta_{\mathrm{H}}$-Spectrin at later stages. $\alpha$-spectrin mutant follicle cells retain lateral $\beta$-Spectrin, suggesting that recruitment of $\beta$-Spectrin to the basolateral membrane is independent of $\alpha$-Spectrin (73). Also, follicle cells that lack $\beta_{\mathrm{H}^{-}}$Spectrin form a follicular epithelium but lose apical $\alpha$-Spectrin. No polarity defects are detected in karst mutant follicle cells. However, fragmentation of the ZA is observed in karst mutant follicle cells as they migrate posteriorly to cover the oocyte. At this time follicle cells in karst mutants fail to constrict apically, suggesting that $\beta_{\mathrm{H}^{-}}$Spectrin may stabilize the ZA during apical constriction $(159,190)$. These results suggest that the defects seen in $\alpha$-spectrin mutants are largely independent of $\beta_{\mathrm{H}^{-}}$Spectrin, and that $\beta_{\mathrm{H}^{-}}$Spectrin is involved in maintaining the ZA during epithelial morphogenesis.

\section{CONCLUSIONS AND PROSPECTS}

The recent progress in our understanding of the mechanisms involved in epithelial polarization has focused our attention on a number of protein complexes that play essential roles in the formation of distinct plasma membrane domains. These protein complexes either congregate around transmembrane proteins (Cadherin, $\mathrm{Crb}, \mathrm{Nrx}-\mathrm{IV}$ ) or represent cytocortical protein assemblies for which the mechanism of plasma membrane association remains obscure (Baz/Par-3 complex, Lgl complex). Additional components of these protein complexes and molecular interactions within these complexes remain to be characterized. Further, a remaining major challenge is to uncover how the activity of these complexes is integrated to generate a single polarized cellular architecture. How, for example, does the Crb complex control ZA formation and how, in turn, do adherens junctions control the stability of the Crb complex? Similarly, how does the Lgl complex, which localizes to the lateral membrane, confine the extent of the apical domain? These functional relationships suggest connections between these complexes, either in the form of physical linkages or perhaps via intracellular signaling pathways, which are currently not understood.

We have not discussed in detail a number of additional Drosophila genes that act in epithelial differentiation because their function and their relation to the larger themes elaborated in this review are not well understood. Among these genes is bloated tubules, which encodes a transmembrane protein related to vertebrate neurotransmitter symporters and controls the extent of the apical domain in Malphigian tubules (60). The arc gene encodes a PDZ domain protein that associates with the marginal zone and/or ZA of portions of embryonic and imaginal 
epithelia and controls the morphogenesis of imaginal discs (79). faint sausage encodes a GPI anchored adhesion molecule of the immunoglobulin superfamily and is required for maintenance of epithelial intergity from mid- to late-embryogenesis (77). Moesin and Merlin, members of the Protein 4.1 superfamily, are found in the apical region of epithelial cells (90). Merlin mutations do not appear to affect overall cell polarity (67), and the effects of Moesin mutations on polarity and epithelial integrity are currently being examined (O. Nikiforova \& R. Fehon, unpublished results). A major challenge for the near future will be to explore the activity and molecular interactions of these proteins, and other yet unidentified genes that play a role in epithelial polarity. Moreover, one issue that plays a central role in the discussion of epithelial polarity in mammalian cell culture models, the contribution of protein and lipid sorting in the biosynthetic pathway, has so far not been vigorously pursued in Drosophila.

Intriguing parallels and differences become apparent when polarity in epithelial cells and non-epithelial neuroblasts are compared. Neuroblasts in Drosophila (similar to the one-cell C. elegans embryo and budding yeast) have two surface domains, an apical and a basal domain (anterior and posterior in C. elegans and bud site versus non-bud site in yeast) $(30,81,122)$. In contrast, in differentiated epithelial cells we can distinguish at least six membrane domains, the free apical surface, the marginal zone, the ZA, the SJ, the lateral membrane basal to the SJ, and the basal membrane. Only the Baz/Par-3 complex and the Lgl complex act in both neuroblast and epithelial polarity, whereas the complexes that associate with Cadherin, Crb, and Nrx-IV are not needed for neuroblast polarity. This comparison emphasizes the central role of adhesive interactions mediated by transmembrane adhesion receptors in defining epithelial membrane domains. Moreover, it raises the question of how the polarized cortical localization of the Baz/Par-3 complex and the $\mathrm{Lgl} \mathrm{complex} \mathrm{is} \mathrm{generated} \mathrm{in} \mathrm{epithelial} \mathrm{cells} \mathrm{and} \mathrm{neuroblasts} \mathrm{in} \mathrm{the} \mathrm{absence}$ of any known transmembrane components or other localization cues. Two inferences can be drawn from these observations. First, we may view polarity as seen in yeast, the C. elegans embryo, or Drosophila neuroblasts as a simpler form of cell polarization that is elaborated upon in epithelial cells by the impact of cell adhesion receptors and their associated protein complexes. Second, we are still far from fully understanding the mechanisms by which the intricate cellular architecture of epithelial cells, or even the relatively simpler polarized organization of other cells, is established and maintained in developing organisms.

\section{ACKNOWLEDGMENTS}

We are grateful to Y. Hong, Y. N. Jan, E. Knust, M. Peifer, G. Thomas and A. Wodarz for communicating results prior to publication. We thank D. Godt and J. Genova for critical comments on the manuscript. This work was supported by grants from the Canadian Institute of Heath Research and the Canadian Cancer Institute (to U. T.) and by grants from the American Cancer Society (RPG-97-02604-DDC) and the National Institutes of Health (NS34783) (to R. F.). 


\section{Visit the Annual Reviews home page at www.AnnualReviews.org}

\section{LITERATURE CITED}

1. Abbott LA, Natzle JE. 1992. Epithelial polarity and cell separation in the neoplastic l(1)dlg-1 mutant of Drosophila. Mech. Dev. 37:43-56

2. Adam JC, Pringle JR, Peifer M. 2000. Evidence for functional differentiation among Drosophila septins in cytokinesis and cellularization. Mol. Biol. Cell 11: 3123-35

3. Adams MD, Celniker SE, Holt RA, Evans CA, Gocayne JD, et al. 2000. The genome sequence of Drosophila melanogaster. Science 287:2185-95

4. Afshar K, Stuart B, Wasserman SA. 2000. Functional analysis of the Drosophila diaphanous $\mathrm{FH}$ protein in early embryonic development. Development 127:1887-97

5. Anderson RA, Lovrien RE. 1984. Glycophorin is linked by band 4.1 protein to the human erythrocyte membrane skeleton. Nature 307:655-58

6. Auld VJ, Fetter RD, Broadie K, Goodman CS. 1995. Gliotactin, a novel transmembrane protein on peripheral glia, is required to form the blood-nerve barrier in Drosophila. Cell 81:757-67

7. Bachmann A, Schneider M, Theilenberg E, Grawe F, Knust E. 2001. Stardust, a novel Drosophila MAGUK, acts as a partner of Crumbs in the control of epithelial polarity. Nature. In press

8. Baumgartner S, Littleton JT, Broadie K, Bhat MA, Harbecke R, et al. 1996. A Drosophila neurexin is required for septate junction and blood-nerve barrier formation and function. Cell 87:1059-68

9. Bellen HJ, Lu Y, Beckstead R, Bhat MA. 1998. Neurexin IV, caspr and paranodinnovel members of the neurexin family: encounters of axons and glia. Trends $\mathrm{Neu}$ rosci. 21:444-49

10. Berrueta L, Kraeft SK, Tirnauer JS,
Schuyler SC, Chen LB, et al. 1998. The adenomatous polyposis coli-binding protein EB1 is associated with cytoplasmic and spindle microtubules. Proc. Natl. Acad. Sci. USA 95:10596-601

11. Bhat MA, Izaddoost $\mathrm{S}$, Lu Y, Cho KO, Choi KW, Bellen H. 1999. Discs Lost, a novel multi-PDZ domain protein, establishes and maintains epithelial polarity. Cell 96:633-45

12. Bhat MA, Rios JC, Lu Y, Garcia-Fresco GP, Ching W, et al. 2001 Axon-glia interactions and the domain organization of myelinated axons requires neurexin IV/Caspr/Paranodin. Neuron 30:369-83

13. Bilder D, Birnbaum D, Borg JP, Bryant P, Huigbretse J, et al. 2000. Collective nomenclature for LAP proteins. Nat. Cell Biol. 2:E114

14. Bilder D, Li M, Perrimon N. 2000. Cooperative regulation of cell polarity and growth by Drosophila tumor suppressors. Science 289:113-16

15. Bilder D, Perrimon N. 2000. Localization of apical epithelial determinants by the basolateral PDZ protein Scribble. $\mathrm{Na}$ ture 403:676-80

16. Borg JP, Marchetto S, Le Bivic A, Ollendorff V, Jaulin-Bastard F, et al. 2000. ERBIN: a basolateral PDZ protein that interacts with the mammalian ERBB2/ HER2 receptor. Nat. Cell Biol. 2:40714

17. Bossinger $\mathrm{O}$, Klebes A, Segbert C, Theres C, Knust E. 2001. Zonula adherens formation in Caenorhabditis elegans requires $d l g-1$, the homologue of the Drosophila gene discs large. Dev. Biol. 230:29-42

18. Boyle ME, Berglund EO, Murai KK, Weber L, Peles E, Ranscht B. 2001. Contactin orchestrates assembly of the septate-like junctions at the paranode 
in myelinated peripheral nerve. Neuron 30:385-97

19. Bridges CB, Brehme KS. 1944. The Mutants of Drosophila melanogaster. Carnegie Inst.

20. Brown NH, Gregory SL, MartinBermudo MD. 2000. Integrins as mediators of morphogenesis in Drosophila. Dev. Biol. 223:1-16

21. Burgess RW, Deitcher DL, Schwarz TL. 1997. The synaptic protein syntaxin1 is required for cellularization of Drosophila embryos. J. Cell Biol. 138:861-75

22. Cagan RL, Kramer H, Hart AC, Zipursky SL. 1992. The bride of sevenless and sevenless interaction: internalization of a transmembrane ligand. Cell 69:393-99

23. Cantallops I, Cline HT. 2000. Synapse formation: if it looks like a duck and quacks like a duck... . Curr. Biol. 10:R620-23

24. Carlson SD, Hilgers SL, Juang JL. 1997. Ultrastructure and blood-nerve barrier of chordotonal organs in the Drosophila embryo. J. Neurocytol. 26:377-88

25. Carlson SD, Juang JL, Hilgers SL, Garment MB. 2000. Blood barriers of the insect. Annu. Rev. Entomol. 45:151-74

26. Chishti AH, Kim AC, Marfatia SM, Lutchman M, Hanspal M, et al. 1998. The FERM domain: a unique module involved in the linkage of cytoplasmic proteins to the membrane. Trends Biochem. Sci. 23:281-82

27. Cox RT, Kirkpatrick C, Peifer M. 1996. Armadillo is required for adherens junction assembly, cell polarity, and morphogenesis during Drosophila embryogenesis. J. Cell Biol. 134:133-48

28. Crawford JM, Harden N, Leung T, Lim L, Kiehart DP. 1998. Cellularization in Drosophila melanogaster is disrupted by the inhibition of rho activity and the activation of $\mathrm{Cdc} 42$ function. Dev. Biol. 204:151-64

29. den Hollander AI, ten Brink JB, de Kok YJ, van Soest S, van den Born LI, et al. 1999. Mutations in a human homologue of Drosophila crumbs cause retinitis pigmentosa (RP12). Nat. Genet. 23:217-21

30. Drubin DG, Nelson WJ. 1996. Origins of cell polarity. Cell 84:335-44

31. Dubreuil RR, Frankel J, Wang P, Howrylak J, Kappil M, Grushko TA. 1998. Mutations of $\alpha$-spectrin and labial block cuprophilic cell differentiation and acid secretion in the middle midgut of Drosophila larvae. Dev. Biol. 194:111

32. Dubreuil RR, Grushko T. 1998. Genetic studies of spectrin: new life for a ghost protein. BioEssays 20:875-78

33. Dubreuil RR, Maddux PB, Grushko TA, MacVicar GR. 1997. Segregation of two spectrin isoforms: polarized membrane-binding sites direct polarized membrane skeleton assembly. Mol. Biol. Cell 8:1933-42

34. Dubreuil RR, Wang P, Dahl S, Lee J, Goldstein LS. 2000. Drosophila $\beta$ spectrin functions independently of $\alpha$ spectrin to polarize the $\mathrm{Na}, \mathrm{K}$ ATPase in epithelial cells. J Cell Biol. 149:64756

35. Dubreuil RR, Yu J. 1994. Ankyrin and $\beta$ spectrin accumulate independently of $\alpha$ spectrin in Drosophila. Proc. Natl. Acad. Sci. USA 91:10285-89

36. Einheber S, Zanazzi G, Ching W, Scherer S, Milner TA, et al. 1997. The axonal membrane protein Caspr, a homologue of neurexin IV, is a component of the septate-like paranodal junctions that assemble during myelination. J. Cell Biol. 139:1495-506

37. Faivre-Sarrailh C, Gauthier F, Denisenko-Nehrbass N, Le Bivic A, Rougon G, Girault JA. 2000. The glycosylphosphatidyl inositol-anchored adhesion molecule F3/ contactin is required for surface transport of paranodin/contactinassociated protein (caspr). J. Cell Biol. 149:491-502

38. Farquhar MG, Palade GE. 1963. Junctional complexes in various epithelia. $J$. Cell Biol. 17:375-412 
39. Fehon RG, Dawson IA, ArtavanisTsakonas S. 1994. A Drosophila homologue of membrane-skeleton protein 4.1 is associated with septate junctions and is encoded by the coracle gene. Development 120:545-57

40. Fehon RG, Johansen K, Rebay I, Artavanis-Tsakonas S. 1991. Complex cellular and subcellular regulation of Notch expression during embryonic and imaginal development of implications for Notch function. J. Cell Biol. 113:657-69

41. Field CM, Alberts BM. 1995. Anillin, a contractile ring protein that cycles from the nucleus to the cell cortex. J. Cell Biol. 131:165-78

42. Foe VE, Alberts BM. 1983. Studies of nuclear and cytoplasmic behaviour during the five mitotic cycles that precede gastrulation in Drosophila embryogenesis. J. Cell Sci. 61:31-70

43. Foe VE, Odell GM, Edgar BA. 1993. Mitosis and morphogenesis in the Drosophila embryo: Point and counterpoint. In The Development of Drosophila melanogaster, ed. M Bate, A Martinez-Arias, pp. 149-300. Plainview, NY: CSHL Press

44. Fullilove SL, Jacobson AG. 1971. Nuclear elongation and cytokinesis in Drosophila montana. Dev. Biol. 26:560-77

45. Gateff E. 1978. Malignant neoplasms of genetic origin in Drosophila melanogaster. Science 200:1448-59

46. Genova JL, Jong S, Camp JT, Fehon RG. 2000. Functional analysis of Cdc42 in actin filament assembly, epithelial morphogenesis, and cell signaling during Drosophila development. Dev. Biol. 221: 181-94

47. Gilbert M, Smith J, Roskams AJ, Auld VJ. 2001. Neuroligin 3 is a vertebrate gliotactin expressed in the olfactory ensheathing glia, a growth-promoting class of macroglia. Glia 34:151-64

48. Godt D, Tepass U. 1998. Drosophila oocyte localization is mediated by differential cadherin-based adhesion. Nature 395:387-91
49. Gotta M, Abraham MC, Ahringer J. 2001. CDC-42 controls early cell polarity and spindle orientation in C. elegans. Curr. Biol. 11:482-88

50. Grawe F, Wodarz A, Lee B, Knust E, Skaer H. 1996. The Drosophila genes crumbs and stardust are involved in the biogenesis of adherens junctions. Development 122:951-59

51. Grindstaff KK, Yeaman C, Anandasabapathy N, Hsu SC, Rodriguez-Boulan E, et al. 1998. Sec6/8 complex is recruited to cell-cell contacts and specifies transport vesicle delivery to the basal-lateral membrane in polarized epithelial cells. Cell 93:731-40

52. Haag TA, Haag NP, Lekven AC, Hartenstein V. 1999. The role of cell adhesion molecules in Drosophila heart morphogenesis: faint sausage, shotgun/DEcadherin, and laminin A are required for discrete stages in heart development. Dev. Biol. 208:56-69

53. Hales KG, BiE, Wu JQ, Adam JC, Yu IC, Pringle JR. 1999. Cytokinesis: an emerging unified theory for eukaryotes? Curr. Opin. Cell Biol. 11:717-12

54. Hong Y, Stronach B, Perrimon N, Jan LY, Jan YN. 2001. Stardust interacts with Crumbs to control polarity of epithelia but neuroblasts in Drosophila. $\mathrm{Na}$ ture. In press

55. Hunter C, Wieschaus E. 2000. Regulated expression of nullo is required for the formation of distinct apical and basal adherens junctions in the Drosophila blastoderm. J. Cell Biol. 150:391-401

56. Ikeda W, Nakanishi H, Miyoshi J, Mandai K, Ishizaki H, Tanaka M, et al. 1999. Afadin: a key molecule essential for structural organization of cellcell junctions of polarized epithelia during embryogenesis. J. Cell Biol. 146:111732

57. Izumi Y, Hirose $T$, Tamai $Y$, Hirai S, Nagashima Y, et al. 1998. An atypical PKC directly associates and colocalizes at the epithelial tight junction with ASIP, a 
mammalian homologue of Caenorhabditis elegans polarity protein PAR-3. J. Cell Biol. 143:95-106

58. Joberty G, Petersen C, Gao L, Macara IG. 2000. The cell-polarity protein Par6 links Par3 and atypical protein kinase $\mathrm{C}$ to Cdc42. Nat. Cell Biol. 2:531-39

59. Johansson A, Driessens M, Aspenstrom P. 2000. The mammalian homologue of the Caenorhabditis elegans polarity protein PAR-6 is a binding partner for the Rho GTPases Cdc42 and Rac1. J. Cell Sci. 113:3267-75

60. Johnson K, Knust E, Skaer H. 1999. bloated tubules (blot) encodes a Drosophila member of the neurotransmitter transporter family required for organisation of the apical cytocortex. Dev. Biol. 212:440-54

61. Jürgens G, Wieschaus E, Nüsslein-Volhard C, Kluding M. 1984. Mutations affecting the pattern of the larval cuticle in Drosophila melanogaster. II. Zygotic loci on the third chromosome. Wilhelm Roux's Arch. Entwicklungsmech. Org. 193:28395

62. Kagami M, Toh-e A, Matsui Y. 1998. Sro7p, a Saccharomyces cerevisiae counterpart of the tumor suppressor 1(2)gl protein, is related to myosins in function. Genetics 149:1717-27

63. Kay AJ, Hunter CP. 2001. CDC-42 regulates PAR protein localization and function to control cellular and embryonic polarity in C. elegans. Curr. Biol. 11:474-81

64. Klebes A, Knust E. 2000. A conserved motif in Crumbs is required for E-cadherin localisation and zonula adherens formation in Drosophila. Curr. Biol. 10:76-85

65. Kraut R, Chia W, Jan LY, Jan YN, Knoblich JA. 1996. Role of inscuteable in orienting asymmetric cell divisions in Drosophila. Nature 383:50-55

66. Kuchinke U, Grawe F, Knust E. 1998. Control of spindle orientation in Drosophila by the Par-3-related PDZ-domain protein Bazooka. Curr. Biol. 8:1357-65
67. LaJeunesse DR, McCartney BM, Fehon RG. 1998. Structural analysis of Drosophila merlin reveals functional domains important for growth control and subcellular localization. J. Cell Biol. 141:1589-99

68. Lamb RS, Ward RE, Schweizer L, Fehon RG. 1998. Drosophila coracle, a member of the protein 4.1 superfamily, has essential structural functions in the septate junctions and developmental functions in embryonic and adult epithelial cells. Mol. Biol. Cell 9:3505-19

69. Lane NJ. 1991. Morphology of glial blood-brain barriers. Ann. NY Acad. Sci. 633:348-62

70. Lane NJ, Chandler HJ. 1980. Definitive evidence for the existence of tight junctions in invertebrates. J. Cell Biol. 86:76574

71. Lane NJ, Skaer HLB, Swales LS. 1977. Intercellular junctions in the central nervous system of insects. J. Cell Sci. 26:99175

72. Lecuit T, Wieschaus E. 2000. Polarized insertion of new membrane from a cytoplasmic reservoir during cleavage of the Drosophila embryo. J. Cell Biol. 150:849-60

73. Lee JK, Brandin E, Branton D, Goldstein LS. 1997. $\alpha$-Spectrin is required for ovarian follicle monolayer integrity in Drosophila melanogaster. Development 124:353-62

74. Lee JK, Coyne RS, Dubreuil RR, Goldstein LS, Branton D. 1993. Cell shape and interaction defects in $\alpha$-spectrin mutants of Drosophila melanogaster. J. Cell Biol. 123:1797-809

75. Legouis R, Gansmuller A, Sookhareea S, Bosher JM, Baillie DL, Labouesse M. 2000. LET-413 is a basolateral protein required for the assembly of adherens junctions in Caenorhabditis elegans. Nat. Cell Biol. 2:415-22

76. Lehman K, Rossi G, Adamo JE, Brennwald P. 1999. Yeast homologues of tomosyn and lethal giant larvae function 
in exocytosis and are associated with the plasma membrane SNARE, Sec9. J. Cell Biol. 146:125-40

77. Lekven AC, Tepass U, Keshmeshian M, Hartenstein V. 1998. faint sausage encodes a novel extracellular protein of the immunoglobulin superfamily required for cell migration and the establishment of normal axonal pathways in the Drosophila nervous system. Development 125:274758

78. Lin D, Edwards AS, Fawcett JP, Mbamalu G, Scott JD, Pawson T. 2000. A mammalian PAR-3-PAR-6 complex implicated in Cdc42/Rac1and aPKC signalling and cell polarity. Nat. Cell Biol. 2:540-47

79. Liu X, Lengyel JA. 2000. Drosophila arc encodes a novel adherens junctionassociated PDZ domain protein required for wing and eye development. Dev. Biol. 221:419-34

80. Loncar D, Singer SJ. 1995. Cell membrane formation during the cellularization of the syncytial blastoderm of Drosophila. Proc. Natl. Acad. Sci. USA 92:2199-203

81. Lu B, Jan L, Jan YN. 2000. Control of cell divisions in the nervous system: symmetry and asymmetry. Annu. Rev. Neurosci. 23:531-56

82. Lu B, Roegiers F, Jan LY, Jan YN. 2001. Adherens junctions inhibit asymmetric division in the Drosophila epithelium. $\mathrm{Na}$ ture 409:522-25

83. Lue RA, Brandin E, Chan EP, Branton D. 1996. Two independent domains of $\mathrm{hDlg}$ are sufficient for subcellular targeting: the PDZ1-2 conformational unit and an alternatively spliced domain. $J$. Cell Biol. 135:1125-37

84. Mandai K, Nakanishi H, Satoh A, Obaishi H, Wada M, et al. 1997. Afadin: a novel actin filament-binding protein with one PDZ domain localized at cadherinbased cell-to-cell adherens junction. $J$. Cell Biol. 139:517-28

85. Mandai K, Nakanishi H, Satoh A, Takahashi K, Satoh K, et al. 1999. An l-afadin- and vinculin-binding protein localized at cell-cell and cell-matrix adherens junctions. J. Cell Biol. 144:1001-17

86. Marfatia SM, Lue RA, Branton D, Chishti AH. 1994. In vitro binding studies suggest a membrane-associated complex between erythroid p55, protein 4.1, and glycophorin C. J. Biol. Chem. 269:863134

87. Matsuo T, Takahashi K, Kondo S, Kaibuchi K, Yamamoto D. 1997. Regulation of cone cell formation by Canoe and Ras in the developing Drosophila eye. Development 124:2671-80

88. Matsuo T, Takahashi K, Suzuki E, Yamamoto D. 1999. The Canoe protein is necessary in adherens junctions for development of ommatidial architecture in the Drosophila compound eye. Cell Tissue Res. 298:397-404

89. McCartney BM, Dierick HA, Kirkpatrick C, Moline MM, Baas A, et al. 1999. Drosophila APC2 is a cytoskeletallyassociated protein that regulates wingless signaling in the embryonic epidermis. $J$. Cell Biol. 146:1303-18

90. McCartney BM, Fehon RG. 1996. Distinct cellular and subcellular patterns of expression imply distinct functions for the Drosophila homologues of moesin and the neurofibromatosis 2 tumor suppressor, merlin. J. Cell Biol. 133:843-52

91. McEwen DG, Cox RT, Peifer M. 2000. The canonical $\mathrm{Wg}$ and JNK signaling cascades collaborate to promote both dorsal closure and ventral patterning. Development 127:3607-17

91a. McMahon L, Legouis R, Vonesch JL, Labouesse M. 2001. Assembly of C. elegans apical junctions involves positioning and compaction by LET-413 and protein aggregation by the MAGUK protein DLG-1. J. Cell Sci. 114:2265-77

92. McNeill H, Ozawa M, Kemler R, Nelson WJ. 1990. Novel function of the cell adhesion molecule uvomorulin as an inducer of cell surface polarity. Cell 62:30916 
93. Mechler BM, McGinnis W, Gehring WJ. 1985. Molecular cloning of lethal(2)giant larvae, a recessive oncogene of Drosophila melanogaster. EMBO J. 4:1551-57

94. Menegoz M, Gaspar P, Le Bert M, Galvez T, Burgaya F, et al. 1997. Paranodin, a glycoprotein of neuronal paranodal membranes. Neuron 19:319-31

95. Miyamoto H, Nihonmatsu I, Kondo S, Ueda R, Togashi S, et al. 1995. canoe encodes a novel protein containing a GLGF/DHR motif and functions with Notch and scabrous in common developmental pathways in Drosophila. Genes Dev. 9:612-25

96. Müller HA. 2000. Genetic control of epithelial cell polarity: lessons from Drosophila. Dev. Dyn. 218:52-67

97. Müller HA, Wieschaus E. 1996. armadillo, bazooka, and stardust are critical for early stages in formation of the zonula adherens and maintenance of the polarized blastoderm epithelium in Drosophila. J. Cell Biol. 134:14963

98. Müsch A, Xu H, Shields D, RodriguezBoulan E. 1996. Transport of vesicular stomatitis virus $G$ protein to the cell surface is signal mediated in polarized and nonpolarized cells. J. Cell Biol. 133:543-58

99. Nakaya M, Fukui A, Izumi Y, Akimoto K, Asashima M, Ohno S. 2000. Meiotic maturation induces animal-vegetal asymmetric distribution of aPKC and ASIP/PAR-3 in Xenopus oocytes. Development 127:5021-31

100. Nelson WJ, Yeaman C, Grindstaff KK. 2000. Spatial cues for cellular asymmetry in polarized epithelia. In Cell Polarity, ed. DG Drubin, pp. 106-40. Oxford/New York: Oxford Univ. Press

100a. Noirot-Timothée C, Noirot C. 1980. Septate and scalariform junctions in arthropods. Int. Rev. Cytol. 63:97-141

101. Noselli S, Agnes F. 1999. Roles of the JNK signaling pathway in Drosophila morphogenesis. Curr. Opin. Genet. Dev. 9:466-72

102. Nüsslein-Volhard C, Wieschaus E, Kluding M. 1984. Mutations affecting the pattern of the larval cuticle in Drosophila melanogaster. I. Zygotic loci on the second chromosome. Wilhelm Roux's Arch. Entwicklungsmech. Org. 193:267-282

103. Oda H, Uemura T, Harada Y, Iwai Y, Takeichi M. 1994. A Drosophila homolog of cadherin associated with Armadillo and essential for embryonic cellcell adhesion. Dev. Biol. 165:716-26

104. Oda H, Uemura T, Shiomi T, Nagafuchi A, Tsukita S, Takeichi M. 1993. Identification of a Drosophila homologue of $\alpha$-catenin and its association with the armadillo protein. J. Cell Biol. 121:113340

105. Oda H, Uemura T, Takeichi M. 1997. Phenotypic analysis of null mutants for DE-cadherin and Armadillo in Drosophila ovaries reveals distinct aspects of their functions in cell adhesion and cytoskeletal organization. Genes Cells 2:29-40

106. Ohshiro T, Yagami T, Zhang C, Matsuzaki F. 2000. Role of cortical tumoursuppressor proteins in asymmetric division of Drosophila neuroblast. Nature 408:593-96

107. Pai, L, Kirkpatrick C, Blanton, J, Oda, H, Takeichi M, Peifer M. 1996. $\alpha$ catenin and DE-cadherin bind to distinct regions of Drosophila Armadillo. J. Biol. Chem. 271:32411-20

108. Pedraza L, Huang JK, Colman DR. 2001. Organizing principles of the axoglial apparatus. Neuron 30:335-44

109. Peifer M. 1993. The product of the Drosophila segment polarity gene armadillo is part of a protein complex resembling the vertebrate adherens junction. J. Cell Sci. 105:993-1000

110. Peifer M, Orsulic S, Sweeton D, Wieschaus E. 1993. A role for the Drosophila segment polarity gene armadillo in cell 
adhesion and cytoskeletal integrity during oogenesis. Development 118:1191207

111. Peifer M, Polakis P. 2000. Wnt signaling in oncogenesis and embryogenesisa look outside the nucleus. Science 287:1606-9

112. Pellikka M, Tanentzapf G, Pinto M, Ready DF, Tepass U. 2001. Crumbs, the Drosophila homolog of human $\mathrm{CRB} 1 / \mathrm{RP} 12$, is essential for photoreceptor morphogenesis. Submitted

113. Peng CY, Manning L, Albertson R, Doe CQ. 2000. The tumour-suppressor genes $l g l$ and $d l g$ regulate basal protein targeting in Drosophila neuroblasts. $\mathrm{Na}$ ture 408:596-600

114. Perrimon N. 1988. The maternal effect of lethal(1)discs-large-1: a recessive oncogene of Drosophila melanogaster. Dev. Biol. 127:392-407

115. Petronczki M, Knoblich JA. 2001. DmPAR-6 directs epithelial polarity and asymmetric cell division of neuroblasts in Drosophila. Nat. Cell Biol. 3:43-49

116. Phelan P, Starich TA. 2001. Innexins get into the gap. BioEssays 23:388-96

117. Postner MA, Wieschaus EF. 1994. The Nullo protein is a component of the actinmyosin network that mediates cellularization in Drosophila melanogaster embryos. J. Cell Sci. 107:1863-73

118. Prokop A, Martin-Bermudo MD, Bate M, Brown NH. 1998. Absence of PS integrins or laminin A affects extracellular adhesion, but not intracellular assembly, of hemiadherens and neuromuscular junctions in Drosophila embryos. Dev. Biol. 196:58-76

119. Qiu RG, Abo A, Steven Martin G. 2000. A human homolog of the C. elegans polarity determinant Par-6 links Rac and $\mathrm{Cdc} 42$ to $\mathrm{PKC} \zeta$ signaling and cell transformation. Curr. Biol. 10:697-707

120. Reinacher-Schick A, Gumbiner BM. 2001. Apical membrane localization of the adenomatous polyposis coli tumor suppressor protein and subcellular distri- bution of the $\beta$-catenin destruction complex in polarized epithelial cells. J. Cell Biol. 152:491-502

121. Rodriguez-Boulan E, Nelson WJ. 1989. Morphogenesis of the polarized epithelial cell phenotype. Science 245:718-25

122. Rose LS, Kemphues KJ. 1998. Early patterning of the C. elegans embryo. Annu. Rev. Genet. 32:521-45

123. Rothwell WF, Fogarty P, Field CM, Sullivan W. 1998. Nuclear-fallout, a Drosophila protein that cycles from the cytoplasm to the centrosomes, regulates cortical microfilament organization. $D e$ velopment $125: 1295-303$

124. Rothwell WF, Zhang CX, Zelano C, Hsieh TS, Sullivan W. 1999. The Drosophila centrosomal protein Nuf is required for recruiting Dah, a membrane associated protein, to furrows in the early embryo. J. Cell Sci. 112:2885-93

125. Schejter ED, Wieschaus E. 1993. bottleneck acts as a regulator of the microfilament network governing cellularization of the Drosophila embryo. Cell 75:37385

126. Schejter ED, Wieschaus E. 1993. Functional elements of the cytoskeleton in the early Drosophila embryo. Annu. Rev. Cell Biol. 9:67-99

127. Schweisguth F, Lepesant JA. Vincent A. 1990 . The serendipity- $\alpha$ gene encodes a membrane-associated protein required for the cellularization of the Drosophila embryo. Genes Dev. 4:922-31

128. Simmonds AJ, dosSantos G, Livne-Bar I, Krause HM. 2001. Apical localization of wingless transcripts is required for wingless signaling. Cell 105:197-207

129. Simon DB, Lu Y, Choate KA, Velazquez H, Al-Sabban E, et al. 1999. Paracellin-1, a renal tight junction protein required for paracellular $\mathrm{Mg}^{2+}$ resorption. Science 285:103-6

130. Simons K, Wandinger-Ness A. 1990. Polarized sorting in epithelia. Cell 1990 62:207-10

131. Simpson L, Wieschaus E. 1990. Zygotic 
activity of the nullo locus is required to stabilize the actin-myosin network during cellularization in Drosophila. Development 110:851-63

132. Sisson JC, Field C, Ventura R, Royou A, Sullivan W. 2000. Lava lamp, a novel peripheral golgi protein, is required for Drosophila melanogaster cellularization. J. Cell Biol. 151:905-18

133. Stevenson BR, Anderson JM, Bullivant S. 1988. The epithelial tight junction: structure, function and preliminary biochemical characterization. Mol. Cell Biochem. 83:129-45

134. Stevenson BR, Siliciano JD, Mooseker MS, Goodenough DA. 1986. Identification of ZO-1: a high molecular weight polypeptide associated with the tight junction (zonula occludens) in a variety of epithelia. J. Cell Biol. 103:75566

135. Strand D, Jakobs R, Merdes G, Neumann B, Kalmes A, et al. 1994. The Drosophila lethal(2)giant larvae tumor suppressor protein forms homo-oligomers and is associated with nonmuscle myosin II heavy chain. J. Cell Biol. 127:1361-73

136. Strand D, Raska I, Mechler BM. 1994. The Drosophila lethal(2)giant larvae tumor suppressor protein is a component of the cytoskeleton. J. Cell Biol. 127:134560

137. Strand D, Unger S, Corvi R, Hartenstein K, Schenkel H, et al. 1995. A human homologue of the Drosophila tumour suppressor gene $l(2) g l$ maps to $17 \mathrm{p} 11.2$ 12 and codes for a cytoskeletal protein that associates with nonmuscle myosin II heavy chain. Oncogene 11:291-301

138. Strutt DI. 2001. Asymmetric localization of Frizzled and the establishment of cell polarity in the Drosophila wing. Mol. Cell 7:367-75

139. Su LK, Burrell M, Hill DE, Gyuris J, Brent R, et al. 1995. APC binds to the novel protein EB1. Cancer Res. 55:2972-77
140. Suzuki A, Yamanaka T, Hirose T, Manabe N, Mizuno K, et al. 2001. Atypical protein kinase $\mathrm{C}$ is involved in the evolutionarily conserved Par protein complex and plays a critical role in establishing epithelia-specific junctional structures. J. Cell Biol. 152:1183-96

141. Tachibana K, Nakanishi H, Mandai K0, Ozaki K, Ikeda W, et al. 2000. Two cell adhesion molecules, nectin and cadherin, interact through their cytoplasmic domain-associated proteins. J. Cell Biol. 150:1161-76

142. Tait S, Gunn-Moore F, Collinson JM, Huang J, Lubetzki C, et al. 2000. An oligodendrocyte cell adhesion molecule at the site of assembly of the paranodal axo-glial junction. J. Cell Biol. 150:65766

143. Takahashi K, Matsuo T, Katsube T, Ueda R, Yamamoto D. 1998. Direct binding between two PDZ domain proteins Canoe and ZO-1 and their roles in regulation of the jun $\mathrm{N}$-terminal kinase pathway in Drosophila morphogenesis. Mech. Dev. 78:97-111

144. Takahashi K, Nakanishi H, Miyahara M, Mandai $\mathrm{K}$, Satoh $\mathrm{K}$, et al. 1999. Nectin/PRR: an immunoglobulinlike cell adhesion molecule recruited to cadherin-based adherens junctions through interaction with Afadin, a PDZ domain containing protein. J. Cell Biol. 145:539-49

145. Takahisa M, Togashi S, Suzuki T, Kobayashi M, Murayama A, et al. 1996. The Drosophila tamou gene, a component of the activating pathway of extramacrochaetae expression, encodes a protein homologous to mammalian cell-cell junction-associated protein ZO-1. Genes Dev. 10:1783-95

146. Takeuchi K, Kawashima A, Nagafuchi A, Tsukita S. 1994. Structural diversity of band 4.1 superfamily members. J. Cell Sci. 107:1921-28

147. Tanentzapf G, Smith C, McGlade J, Tepass U. 2000. Apical, lateral, and basal 
polarization cues contribute to the development of the follicular epithelium during Drosophila oogenesis. J. Cell Biol. 151:891-904

148. Tang AH, Neufeld TP, Rubin GM, Müller HA. 2001. Transcriptional regulation of cytoskeletal functions and segmentation by a novel maternal pair-rule gene, lilliputian. Development 128:80113

149. Tepass U. 1996. Crumbs, a component of the apical membrane, is required for zonula adherens formation in primary epithelia of Drosophila. Dev. Biol. 177:217-25

150. Tepass U. 1997. Epithelial differentiation in Drosophila. BioEssays. 19:67382

151. Tepass U. 1999. Genetic analysis of cadherin function in animal morphogenesis. Curr. Opin. Cell Biol. 11:540-48

152. Tepass U, Gruszynski-de Feo E, Haag TA, Omatyar L, Török T, Hartenstein V. 1996. shotgun encodes Drosophila Ecadherin and is preferentially required during cell rearrangement in the neuroectoderm and other morphogenetically active epithelia. Genes Dev. 10:672-85

153. Tepass U, Hartenstein V. 1994. Epithelium formation in the Drosophila midgut depends on the interaction of endoderm and mesoderm. Development 120:57990

154. Tepass U, Hartenstein V. 1994. The development of cellular junctions in the Drosophila embryo. Dev. Biol. 161:56396

155. Tepass U, Knust E. 1990. Phenotypic and developmental analysis of mutations at the crumbs locus, a gene required for the development of epithelia in Drosophila melanogaster. Roux's Arch. Dev. Biol. 199:189-206

156. Tepass U, Knust E. 1993. crumbs and stardust act in a genetic pathway that controls the organization of epithelia in Drosophila melanogaster. Dev. Biol. 158:311-26
157. Tepass U, Theres C, Knust E. 1990. crumbs encodes an EGF-like protein expressed on apical membranes of Drosophila epithelial cells and required for organization of epithelia. Cell 6:787-99

158. Tepass U, Truong K, Godt D, Ikura M, Peifer M. 2000. Cadherins in embryonic and neural morphogenesis. Nat. Rev. Mol. Cell Biol. 1:91-100

159. Thomas GH. 2001. Spectrin: the ghost in the machine. BioEssays 23:152-60

160. Thomas GH, Kiehart DP. 1994. $\beta_{\text {Heavy }^{-}}$ spectrin has a restricted tissue and subcellular distribution during Drosophila embryogenesis. Development 120 : 2039-50

161. Thomas GH, Williams JA 1999. Dynamic rearrangement of the spectrin membrane skeleton during the generation of epithelial polarity in Drosophila. J. Cell Sci. 112:2843-52

162. Thomas GH, Zarnescu DC, Juedes AE, Bales MA, Londergan A, et al. 1998. Drosophila $\beta_{\text {Heavy-spectrin is essential }}$ for development and contributes to specific cell fates in the eye. Development 125:2125-34

163. Tomlinson A, Bowtell DD, Hafen E, Rubin GM. 1987. Localization of the sevenless protein, a putative receptor for positional information, in the eye imaginal disc of Drosophila. Cell 51:143-50

164. Townsley FM, Bienz M. 2000. Actindependent membrane association of a Drosophila epithelial APC protein and its effect on junctional Armadillo. Curr Biol. 10:1339-48

165. Tsukita S, Furuse M. 2000. Pores in the wall: claudins constitute tight junction strands containing aqueous pores. J. Cell Biol. 149:13-16

166. Turner FR, Mahowald AP. 1976. Scanning electron microscopy of Drosophila embryogenesis. 1 . The structure of the egg envelopes and the formation of the cellular blastoderm. Dev. Biol. 50:95108

167. Uemura T, Oda H, Kraut R, Hayashi 
S, Takeichi M. 1996. Processes of dynamic epithelial cell rearrangement are the major targets of cadE/shotgun mutations in the Drososphila embryo. Genes Dev. 10:659-71

168. Ward RE, Lamb RS, Fehon RG. 1998. A conserved functional domain of Drosophila Coracle is required for localization at the septate junction and has membrane-organizing activity. J. Cell Biol. 140:1463-73

169. Ward RE, Schweizer L, Lamb RS, Fehon RG. 2001. The FERM domain of Drosophila Coracle, a cytoplasmic component of the septate junction, provides functions essential for embryonic development and imaginal cell proliferation. Genetics. In press

170. Wei X, Ellis HM. 2001. Localization of the Drosophila MAGUK protein Polychaetoid is controlled by alternative splicing. Mech. Dev. 100:217-31

171. Welsch U, Buchheim W. 1977. Freeze fracture studies on the annelid septate junction. Cell Tissue Res. 185:527-34

172. Welte MA, Gross SP, Postner M, Block SM, Wieschaus EF. 1998. Developmental regulation of vesicle transport in Drosophila embryos: forces and kinetics. Cell 92:547-57

173. White P, Aberle H, Vincent JP 1998. Signaling and adhesion activities of mammalian $\beta$-catenin and plakoglobin in Drosophila. J. Cell Biol. 140:183-95

174. Wieschaus E, Noell E. 1986. Specificity of embryonic lethal mutations in Drosophila analyzed in germ line clones. Roux's Arch Dev. Biol. 195:63-73

175. Wieschaus E, Nüsslein-Volhard C, Jürgens G. 1984. Mutations affecting the pattern of the larval cuticle in Drosophila melanogaster. III. Zygotic loci on the X-chromosome and fourth chromosome. Wilhelm Roux's Arch. Entwicklungsmech. Org. 193:296-307

176. Wiley CA, Ellisman MH. 1980. Rows of dimeric-particles within the axolemma and juxtaposed particles within glia, in- corporated into a new model for the paranodal glial- axonal junction at the node of Ranvier. J. Cell Biol. 84:261-80

177. Wilk R, Reed BH, Tepass U, Lipshitz HD. 2000. The hindsight gene is required for epithelial maintenance and differentiation of the tracheal system in Drosophila. Dev. Biol. 219:183-96

178. Wodarz A, Grawe F, Knust E. 1993. Crumbs in involved in the control of apical protein targeting during Drosophila epithelial development. Mech. Dev. 44:175-87

179. Wodarz A, Hinz U, Engelbert M, Knust E. 1995. Expression of Crumbs confers apical character on plasma membrane domains of ectodermal epithelia of Drosophila. Cell 82:67-76

180. Wodarz A, Ramrath A, Grimm A, Knust E. 2000. Drosophila atypical protein kinase $\mathrm{C}$ associates with Bazooka and controls polarity of epithelia and neuroblasts. J. Cell Biol. 150:1361-74

181. Wood RL. 1990. The septate junction limits mobility of lipophilic markers in plasma membranes of Hydra vulgaris (attenuata). Cell Tissue Res. 259:61-66

182. Woods DF, Bryant PJ. 1989. Molecular cloning of the lethal (1) discs large1 oncogene of Drosophila. Dev. Biol. 134:222-35

183. Woods DF, Bryant PJ. 1991. The discs-large tumor suppressor gene of Drosophila encodes a guanylate kinase homolog localized at septate junctions. Cell 66:451-64

184. Woods DF, Hough C, Peel D, Callaini G, Bryant PJ. 1996. Dlg protein is required for junction structure, cell polarity, and proliferation control in Drosophila epithelia. J. Cell Biol. 134: 1469-82

185. Yeaman C, Grindstaff KK, Nelson WJ. 1999. New perspectives on mechanisms involved in generating epithelial cell polarity. Physiol. Rev. 79:73-98

186. Yoshimori T, Keller P, Roth MG, Simons K. 1996. Different biosynthetic 
transport routes to the plasma membrane in BHK and CHO cells. J. Cell Biol. 133:247-56

187. Yu X, Waltzer L, Bienz M. 1999. A new Drosophila APC homologue associated with adhesive zones of epithelial cells. Nat. Cell Biol. 1:144-51

188. Zak NB, Shilo BZ. 1992. Localization of DER and the pattern of cell divisions in wild-type and Ellipse eye imaginal discs. Dev. Biol. 149:448-56

189. Zalokar M, Erk I. 1976. Division and migration of nuclei during early embryogenesis of Drosophila melanogaster. J. Microbiol. Cell 25:97-106

190. Zarnescu DC, Thomas GH. 1999. Apical spectrin is essential for epithelial morphogenesis but not apicobasal polarity in Drosophila. J. Cell Biol. 146:107586

191. Zhang CX, Lee MP, Chen AD, Brown SD, Hsieh T. 1996. Isolation and characterization of a Drosophila gene essential for early embryonic development and formation of cortical cleavage furrows. J. Cell Biol. 134:923-34

192. Zhang CX, Rothwell WF, Sullivan W, Hsieh TS. 2000. Discontinuous actin hexagon, a protein essential for cortical furrow formation in Drosophila, is membrane associated and hyperphosphorylated. Mol. Biol. Cell 11:1011-22 


\section{ConTENTS}

HyPOVIRUSES AND CHESTNUT BLIGHT: EXPLOITING VIRUSES TO Understand AND Modulate Fungal Pathogenesis, Angus $L$. Dawe and Donald L. Nuss

GENETICS AND THE FITNESS OF HYBRIDS, John M. Burke and Michael L. Arnold

RECOMBINATIONAL DNA REPAIR OF DAMAGED REPLICATION FORKS IN ESCHERICHIA COLI : QUESTIONS, Michael M. Cox

Sir Francis Galton AND THE BIRTH OF EugENICS, Nicholas W. Gillham

Building A Multicellular ORganism, Dale Kaiser

THE INHERITANCE OF GENES IN MITOCHONDRIA AND CHLOROPLASTS: LaWs, MECHANISMS, AND MODELS, C. William Birky, $J r$.

The ACTION of Molecular Chaperones in the EARly SeCRETORY PATHWAY, Sheara W. Fewell, Kevin J. Travers, Jonathan S. Weissman, and Jeffrey L. Brodsky

CHROMATIN INSULATORS AND BOUNDARIES: EFFECTS ON TRANSCRIPTION AND NUCLEAR ORGANIZATION, Tatiana I. Gerasimova and Victor G. Corces

ANIMAL MODELS OF TUMOR-SUPPRESSOR GENES, Razqallah Hakem and Tak W. Mak

HOMOLOGOUS RECOMBINATION NEAR AND FAR FROM DNA BREAKS: ALternative ROLES AND CONTRASTING VIEWS, Gerald R. Smith

MECHANISMS OF RETROVIRAL RECOMBINATION, Matteo Negroni and Henri Buc

The Genetic ARChitecture of QuAntitAtive Traits, Trudy F. $C$. Mackay

NeW PERSPECTIVES ON NuCleAR TrANSPORT, Arash Komeili and Erin K. O'Shea

TRANSLATIONAL REGULATION AND RNA LOCALIZATION IN DRoSOPHILA OOCYTES AND EMBRYOS, Oona Johnstone and Paul Lasko CONSERVATION AND DiVERGENCE IN MOLECUlaR MECHANiSMS OF AXIS FormATION, Sabbi Lall and Nipam H. Patel 
REGULATION OF GENE EXPRESSION BY CELL-TO-CELL

COMMUNICATION: ACYL-HOMOSERINE LACTONE QUORUM

Sensing, Clay Fuqua, Matthew R. Parsek, and E. Peter Greenberg

Models and Data on Plant-EnEmy CoEvolution, Joy Bergelson,

Greg Dwyer, and J. J. Emerson

469

Biology of MAMMALIAN L1 RETROTRANSPOSONS, Eric M. Ostertag and Haig H. Kazazian, Jr.

501

DoEs Nonneutral EVOlution SHAPE ObSERVEd PATTERnS OF DNA VARIATION IN ANIMAL MitochONDRIAL GENOMES?, Anne $S$. Gerber, Ronald Loggins, Sudhir Kumar, and Thomas E. Dowling

IDENTIFICATION OF EPILEPSY GENES IN HuMAN AND MOUSE, Miriam H. Meisler, Jennifer Kearney, Ruth Ottman, and Andrew Escayg

Molecular Genetics of Hearing Loss, Christine Petit, Jacqueline Levilliers, and Jean-Pierre Hardelin

GenETIC ANALYSIS OF CALMODULIN AND ITS TARGETS IN SACCHAROMYCES CEREVISIAE, Martha S. Cyert

DiSSEMINATING THE GENOME: JOINING, RESOLVING, AND SEPARATING Sister Chromatids DURING Mitosis AND MEIOSIS, Kim Nasmyth

Epithelial Cell Polarity and Cell Junctions in Drosophila, Ulrich Tepass, Guy Tanentzapf, Robert Ward, and Richard Fehon

INFORMED CONSENT AND OTHER ETHICAL ISSUES IN HUMAN POPULATION GENETICS, Henry T. Greely

G. LEDYARD StebBins AND THE EvOlutionARy SynTHESIS, Vassiliki Betty Smocovitis

803

INDEXES

Subject Index

Cumulative Index of Contributing Authors, Volumes 31-35

Cumulative Index of Chapter Titles, Volumes 31-35

\section{ERRATA}

An online log of corrections to Annual Review of Genetics chapters may be found at http://genet.AnnualReviews.org/errata.shtml 